University of Nebraska - Lincoln

DigitalCommons@University of Nebraska - Lincoln

2006

Severe Convective Wind Environments

Evan L. Kuchera

Air Force Weather Agency, Offutt AFB, evan.kuchera@afwa.af.mil

Matthew D. Parker

University of Nebraska-Lincoln \& North Carolina State University, Raleigh, parker@updraft.unl.edu

Follow this and additional works at: https://digitalcommons.unl.edu/natrespapers

Part of the Natural Resources and Conservation Commons, Natural Resources Management and Policy Commons, and the Other Environmental Sciences Commons

Kuchera, Evan L. and Parker, Matthew D., "Severe Convective Wind Environments" (2006). Papers in Natural Resources. 1220.

https://digitalcommons.unl.edu/natrespapers/1220

This Article is brought to you for free and open access by the Natural Resources, School of at DigitalCommons@University of Nebraska - Lincoln. It has been accepted for inclusion in Papers in Natural Resources by an authorized administrator of DigitalCommons@University of Nebraska - Lincoln. 


\title{
Severe Convective Wind Environments
}

\author{
EVAN L. KUCHERA \\ Air Force Weather Agency, Offutt AFB, Nebraska \\ MATTHew D. PARKER* \\ Department of Geosciences, University of Nebraska at Lincoln, Lincoln, Nebraska
}

(Manuscript received 7 April 2005, in final form 11 November 2005)

\begin{abstract}
Nontornadic thunderstorm winds from long-lived, widespread convective windstorms can have a tremendous impact on human lives and property. To examine environments that support damaging wind producing convection, sounding parameters from Rapid Update Cycle model analyses (at 3-hourly intervals) from 2003 were compared with 7055 reports of damaging winds and 377081 occurrences of lightning. Groundrelative wind velocity was the most effective at discriminating between damaging and nondamaging wind convective environments. Steep surface-based lapse rates (a traditional damaging wind parameter) generally did not discriminate between damaging and nondamaging wind convective environments. Other parameters, such as convective available potential energy, humidity aloft, and lapse rates aloft were moderately discriminating. This paper presents a composite damaging wind algorithm in which the two most discriminatory parameters were combined, yielding more skill than any individual parameter. Damaging wind environments are then examined further through a selection of cases that highlight common severe wind ingredients and failure modes. A primary result is that, even in seemingly favorable environments, when the winds at the top of the inflow layer were either parallel to the convective line or blowing from warm to cold over a front, damaging winds were less likely. In the former case, it appears that the downdraft winds and the cold pool's gust-front-normal flow are not additive. In the latter case, it appears that convection becomes elevated and does not produce downdrafts that reach the surface. Combining the most discriminatory severe wind parameters with knowledge of these severe wind failure modes may help to improve the situational awareness of forecasters.
\end{abstract}

\section{Introduction}

Convectively generated surface winds are a common occurrence in the United States. Most thunderstorms generate outflow winds when evaporative cooling and precipitation loading cause air to become negatively buoyant, descend to the surface, and diverge (e.g., Byers and Braham 1949). Typically these outflow winds do not cause structural damage. However, in intense or organized systems winds can exceed $70 \mathrm{~m} \mathrm{~s}^{-1}$ (Fujita and Wakimoto 1981), easily damaging structures and

\footnotetext{
* Current affiliation: Department of Marine, Earth, and Atmospheric Sciences, North Carolina State University, Raleigh, North Carolina.
}

Corresponding author address: Evan L. Kuchera, AFWA, 106 Peacekeeper Dr., STE 2N3, Offutt AFB, NE 68113-4039.

E-mail: evan.kuchera@afwa.af.mil putting lives at risk. Ashley (2004) found that approximately 21 deaths and 360 injuries occur every year from damaging convective winds, and Fujita and Wakimoto (1981) documented a single widespread, long-lived windstorm that caused nearly a billion dollars in damage. Clearly, severe wind-producing storms are of great concern to operational forecasters. Therefore, a key challenge is discriminating environments that will produce severe winds from environments that will not. Additionally, it is often important to anticipate when convection will organize into widespread damaging windproducing systems, and to anticipate when those systems will decay. This study describes environments in which severe surface winds occurred, and compares them with environments in which convection occurred, but severe surface winds did not.

Previous research has focused on two principal aspects of the severe thunderstorm wind problem: first, strong thunderstorm downdrafts (Fujita and Wakimoto 
1981), and second, convective systems that produce quasi-continuous severe surface winds, such as bow echoes (e.g., Lee et al. 1992b; Weisman 1993) and derechos (e.g., Johns and Hirt 1987; Evans and Doswell 2001). Both are interrelated aspects of the widespread damaging wind problem but are typically addressed separately. It is likely that organized systems produce most damaging winds, since their scale is often an order of magnitude greater than individual thunderstorm downdrafts. However, strong downdrafts embedded within organized systems may be responsible for much of the damage observed.

Thunderstorm downdrafts occur when precipitation loading, evaporative and sublimative cooling, or ice melting lead to negative buoyancy in a convective cloud, and then steep ambient lapse rates and/or more diabatic cooling allow the downdraft air to maintain negative buoyancy as it warms upon descent. When the integrated downdraft buoyancy is large and negative, downdrafts can be intense and, when they reach the surface, rapidly spread out horizontally, sometimes causing damage. Downdrafts can also be driven by dynamic pressure forces in strong convection, such as the rear-flank downdraft or occlusion downdraft in supercells. The reader is referred to Wakimoto (2001) for a more comprehensive review.

Organized mesoscale convective systems [MCSs; see Houze (2004) for a thorough review] can then enhance the probability of severe surface winds in several ways. First, mesoscale cold pools can form when numerous thunderstorms' outflows merge. The mesoscale pressure gradients associated with these cold pools can cause severe winds without any downdrafts. Second, the internal dynamics of organized systems can lead to local enhancements in surface winds when a rear-inflow jet descends to the surface (Weisman 1993). And finally, an MCS's cold pool can perpetuate convective redevelopment in environments that already support severe downdrafts.

The composite environment of the Johns and Hirt (1987) derecho population consisted of high humidity at the surface (dewpoints from $21.5^{\circ}$ to $25.5^{\circ} \mathrm{C}$ ), steep lapse rates from the surface to $850 \mathrm{hPa}$, and $500-\mathrm{hPa}$ winds of around $20 \mathrm{~m} \mathrm{~s}^{-1}$; together these imply strong vertical wind shear and instability. It is possible that as shear and instability increase, pressure gradients and downdrafts intensify, increasing the likelihood of damaging winds (Weisman 1993). In recent decades, it has also been suggested that strong MCSs require sufficient vertical wind shear to offset the surface cold pool's induced circulation (e.g., Rotunno et al. 1988; Weisman and Rotunno 2004). However, ground-relative winds are the cause of surface damage, not wind shear. Even with significant vertical wind shear and CAPE, a slowly moving system produces comparatively weak surface winds. It therefore makes sense that large groundrelative winds aloft are important (e.g., Johns and Hirt 1987): they entail both the shear necessary for system maintenance and fast system speeds (Evans and Doswell 2001).

However, there may be other, more subtle mechanisms that are important in the damaging wind process. For example, vertical wind shear and CAPE are commonly used to forecast damaging winds, hail, and tornadoes, yet damaging winds occur with a different diurnal and seasonal frequency than tornadoes and hail (Kelly et al. 1985). Additionally, when synoptic-scale frontal boundaries (common where convection is observed) are present, strong forcing and nonhomogeneous environments complicate thunderstorm regeneration (Fritsch and Forbes 2001), and other processes may play a role in severe wind production (e.g., Schmidt and Cotton 1989). This study examined numerous atmospheric parameters that may be important to the development of strong downdrafts, organized systems, and damaging convective winds. The goal is to shed light on the processes that are most important in determining where damaging winds actually occur.

The observational and model analysis data, parameter evaluation techniques, and case study methods used in this investigation are detailed in section 2. Section 3 presents parameter evaluation results, the development of a composite wind parameter, and summaries of selected damaging wind case studies. Section 4 then discusses the combined results from the parameter evaluations and case studies, reflecting on how they can be used to forecast damaging winds, as well as ideas for further study.

\section{Methodology}

Atmospheric sounding parameters have long been analyzed to forecast and understand severe convective weather. Proximity soundings have been used near where tornadoes have occurred (Brooks et al. 1994; Rasmussen and Blanchard 1998), and Rapid Update Cycle (RUC; Benjamin et al. 2004) model analysis soundings have also been used because of the sparse network of observed soundings (Thompson et al. 2003; Markowski et al. 2003). Most of these studies were done to determine the likelihood of tornadic occurrence; however, Evans and Doswell (2001) used proximity soundings to investigate derecho environments.

RUC analyses were obtained from the National Centers for Environmental Prediction to develop the parameters in this study. The isobaric model analysis data have a 3-h time interval on the $20-\mathrm{km}$ RUC grid (ver- 
sion implemented 17 April 2002). To use RUC model analyses, one must be confident that the data have an acceptable degree of accuracy. Thompson et al. (2003) compared 149 observed soundings with RUC model analyses and found them to be reasonable, with some inaccuracies for the environment near the surface. They suggested that if RUC proximity soundings were to be used, a large dataset should be utilized to minimize the effect of random errors. The present study used proximity soundings from RUC model analyses associated with over 7000 damaging wind reports. Over 50 parameters were investigated, following published hypotheses for downbursts, derechos, bow echoes, tornadoes, and large hail formation (see Kuchera 2004 for an exhaustive list).

Convective available potential energy (CAPE) and convective inhibition (CIN) were used to quantify the ambient stability and the potential buoyancy of various air parcels within each sounding. All buoyancy calculations used the virtual temperature correction with respect to water vapor, but neglected any liquid water present in the parcel. Because elevated convection may not produce outflow that can penetrate to the surface, the presence of near-surface CAPE may be necessary for surface-based convection, and hence damaging winds, to occur. In contrast, high near-surface CIN may suppress downdrafts and hinder new convective development. This study considered the most unstable ${ }^{1}$ parcel's CAPE (MUCAPE) and CIN (MUCIN) in joules per kilogram. Several other parcel parameters were calculated using a "mean layer" parcel, since updraft air is likely to have the averaged properties of some vertical depth in proximity to where it originated. The mean layer CAPE (MLCAPE) and CIN (MLCIN) were calculated using the averaged lowest $30-\mathrm{hPa}$ parcel temperature and mixing ratio. The mean layer lifted condensation level (MLLCL) in meters was also calculated to test the hypothesis that downdrafts (and damaging downdraft winds) are preferentially initiated by precipitation loading at high cloud bases (Srivastava 1985, 1987; Proctor 1989; Lee et al. 1992a). Higher LCLs also imply a lower surface relative humidity and a deeper subsaturated layer through which precipitation must fall, in turn leading to more latent cooling and a colder surface outflow.

Wind shear parameters were calculated in meters per second using the magnitude of the vector difference between winds at two heights in kilometers above ground level (AGL). In this study, all surface values are

\footnotetext{
${ }^{1}$ The parcel with the highest $\theta_{e}$ in the lowest $300 \mathrm{hPa}$ of the atmosphere is considered the most unstable.
}

represented by the mean layer wind velocity in the lowest $30 \mathrm{hPa}$ (hereafter denoted by " $0 \mathrm{~km}$ " or "surface"). All wind shear (SHR) values are presented as SHR**KM, with the pair of asterisks representing the lower and upper levels. For example, SHR06KM is the magnitude of the vector difference between the surface wind and the wind at $6 \mathrm{~km}$ AGL. Wind velocities at various levels were also calculated in meters per second, with the naming convection WIND*KM where the asterisk is the height of the wind in kilometers AGL. For example, WIND3KM is the wind velocity magnitude at $3 \mathrm{~km}$ AGL. Storm-relative helicity was calculated in joules per kilogram for various depths using the supercell storm motion method outlined in Bunkers et al. (2000), with the exception of calculating the surface$7-\mathrm{km}$ pressure-weighted mean wind instead of the surface-6-km non-pressure-weighted mean wind, which is an acceptable alternative when working with isobaric data (Bunkers et al. 2000). All helicity values are presented as $\mathrm{SRH}^{* *} \mathrm{KM}$, in the same manner as the wind shear values. For example, SRH01KM is the stormrelative helicity integrated from the surface to $1 \mathrm{~km}$ AGL. Wind shear, wind velocity, and helicity are well known to be associated with severe weather, so numerous permutations of each were chosen for study. Shear in the lowest levels is hypothesized to be important in generating vigorous updrafts along thunderstorm outflow boundaries (Rotunno et al. 1988), while helicity is associated with updraft rotation in supercells (DaviesJones 1984), which can produce damaging winds. Ground-relative wind velocities are calculated because the ambient wind field plays a key role in system motion (Corfidi et al. 1996); rapidly moving gust fronts in turn may be associated with damaging winds.

Additionally, several wind parameters were calculated using layers determined by the thermodynamic properties of the sounding. To examine if an atmospheric layer was susceptible to deep, moist convection, a parcel was lifted $400 \mathrm{hPa},{ }^{2}$ and its new temperature compared with the temperature of the environment at that level. If the parcel was warmer than its environment, it was considered "potentially buoyant." If the surface layer was potentially buoyant, parcels for levels above it were successively examined in the same manner until a stable parcel was reached. The total depth of the layer of potentially buoyant parcels was then considered to be the inflow depth for the surface-based convection. The depth of the inflow layer (instead of a fixed layer) was used to calculate the "effective" sur-

\footnotetext{
${ }^{2}$ A parcel was lifted adiabatically to its LCL, and then pseudoadiabatically thereafter.
} 
face-based storm-relative helicity (SRHEFF), again using the Bunkers et al. (2000) storm motion. The wind at the highest positively buoyant level in the surface inflow layer was calculated (WINDINF) and the vector difference between the surface wind and WINDINF was also calculated (SHRINF). To determine the shear in a storm's cloud-bearing layer, the vector difference between the wind at MLLCL and the wind at one-half the cloud-top height ${ }^{3}$ was calculated (SHRCLD). These layers and parameters were hypothesized to have stronger ties to convective processes than those associated with fixed height levels (Thompson et al. 2004). For example, SRHEFF and SHRINF were only calculated using parcels that can be ingested into deep moist convective clouds.

Downdraft CAPE (DCAPE) was calculated using a method similar to that used by Gilmore and Wicker (1998), using the level of minimum equivalent potential temperature $\theta_{e}$. DCAPE values may be used as a rough estimate of downdraft or cold pool strength (Evans and Doswell 2001), both of which can cause damaging winds. Dry air in the midlevels was evaluated by examining the minimum relative humidity from 2-4, 4-6, and 2-6 km AGL in percent (MINRH** KM). For example, MINRH24KM is the minimum relative humidity from 2 to $4 \mathrm{~km}$ AGL. MINRH was calculated because dry air entrainment into convective clouds causes evaporative and sublimative cooling and the release of negative potential buoyancy, which could lead to strong downdrafts and severe surface winds (Proctor 1989). Lapse rates between two heights in kilometers were calculated in degrees kelvin per kilometer (reported as positive numbers) with the naming convention LAPSE**KM, following Srivastava (1985), Wakimoto (1985), and Knupp (1987), who showed that lapse rates were a factor in downdraft strength.

The latitudes, longitudes, and occurrence times of tornadoes, damaging winds (either wind damage or gusts estimated or observed to be higher than 25 $\mathrm{m} \mathrm{s}^{-1}$ ), and large hail (diameter greater than $2 \mathrm{~cm}$ ) as reported in the National Weather Service/Storm Prediction Center's preliminary database ${ }^{4}$ (DOC/NOAA/ NCEP/NWS SPC 2003) were compared with RUC analysis parameters from up to $3 \mathrm{~h}$ before the report occurred. For example, all severe reports from 1200 to

\footnotetext{
${ }^{3}$ The "cloud-top height" was taken to be the most unstable inflow parcel's equilibrium level.

${ }^{4}$ There are several caveats worth mentioning about severe weather reporting, as discussed by Kelly et al. (1985; e.g., wind speeds inferred from damage, and reporting inhomogeneities), but the SPC database provided for a large number of cases that were internally consistent and easy to process.
}

1459 UTC were compared with the 1200 UTC RUC analysis. Tornado and large hail occurrences were compared with damaging wind occurrences to determine if the environment was favorable for all types of severe weather, or just favorable for damaging winds. Next, lightning data from the National Lightning Detection Network (Orville 1991) were compared with RUC model analyses in the same manner. If at least five lightning occurrences were observed within the $20-\mathrm{km}$ RUC grid box in the 3-h period, that grid box was considered a "lightning point" (regardless of whether severe weather occurred there). There were over 500 RUC analyses compared with 958 reports of tornadoes, 6355 reports of hail, 7055 reports of damaging winds, and 377081 lightning points, with one datum for each report.

Percentile values and $T$ scores from the Student's $t$ test were calculated for the parameter distributions associated with the severe reports and lightning points, to show which tornado, wind, and hail distributions were significantly different from the lightning distribution, and to measure how much difference there was. The $T$ score is a difference-of-means test measuring the likelihood that two datasets were not created by randomly selecting their values from a common third dataset. The higher the $T$ score, the higher the likelihood that the two samples are not random subsets of some larger, undifferentiated group. For reference, a $T$ score of 2.81 indicates a $99 \%$ chance that the differences between two datasets are not attributable to random sampling.

Additionally, an optimal Peirce (1884) skill score (OPSS) and threshold value were calculated by examining threshold values for each variable until the highest possible Peirce score was achieved for each severe distribution compared with the lightning distribution. Wilks (1995) showed that the Peirce method (also known as the Hanssen-Kuipers discriminant and the true skill statistic) is useful for verifying forecasts because it is not dependent on sample size. A Peirce score of 1 indicates all forecasts are correct, 0 indicates a random forecast, and -1 indicates all forecasts are incorrect. For example, the Peirce skill score for a damaging wind forecast parameter is calculated from

$$
\frac{(a d-b c)}{(a+c)(b+d)},
$$

where $a$ is the number of damaging wind data points greater than the threshold value (correct forecast of damaging winds), $b$ is the number of lightning points greater than the threshold value (incorrect forecast of damaging winds), $c$ is the number of damaging wind points less than the threshold value (incorrect forecasts of no damaging winds), and $d$ is the number of lightning 
points less than the threshold value (correct forecasts of no damaging winds). The wind and lightning data were also broken down into subcategories by region, month, and time of day (day versus night), but for brevity those results are not included here, as they were generally similar to the overall results (see Kuchera 2004 for details).

Because sounding parameters alone cannot diagnose all aspects of the damaging wind problem, 11 cases were studied to further investigate the reasons damaging winds occurred (four of which will be summarized here). Cases were selected to ensure a variety of environments representative of when damaging winds occurred throughout the year, in different regions of the country, and during different times of day. Of the 11 cases, 4 were considered "events," where widespread damaging winds occurred. Five were considered "nulls," where strong convection occurred but widespread damaging winds did not, often in the presence of other types of severe weather that was widespread. The final two cases were each composed of two convective systems, one of which was an event and the other of which a null. In each case, surface, radar, satellite, profiler, and rawinsonde data were examined in addition to the RUC analysis and lightning data to determine frontal positions, system motion and evolution, and the general environment in which convection was occurring. After all 11 cases were studied, conceptual models were developed to illustrate patterns in which damaging winds occurred, and in which convection occurred but damaging winds did not (presented in section $3 \mathrm{~d}$ ).

\section{Results}

\section{a. Wind parameters}

The first comparisons are for ground-relative wind velocity data for 2003 (Table 1). WIND0KM is somewhat discriminatory for damaging wind points, with an OPSS value of 0.073 and a $T$ score of 12.9 , but it is clear that the winds just above the surface are much more discriminatory. The $T$ score for damaging winds is greatest for WINDINF (51.7) as is the OPSS value (0.286 using a threshold of 8.0), indicating that WINDINF best discriminates (among the groundrelative wind parameters) between ordinary convection and convection with damaging winds (Table 1). Indeed, WINDINF has the highest $T$ score and (again, using a threshold of 8.0) OPSS value among all parameters tested for damaging winds. Among the ground-relative wind parameters, mid- and upper-level winds (Table 1) appear to be the best discriminators between ordinary convection and convection with large hail or tornadoes: the OPSS value for hail (0.366) is maximized using a
TABLE 1. Percentile values $(25,50$, and 75$), T$ scores (TS), OPSS, and the OPSS threshold value (Threshold) of groundrelative wind velocities $\left(\mathrm{m} \mathrm{s}^{-1}\right)$ for reports of tornadoes $(\mathrm{T})$, hail greater than $2 \mathrm{~cm}(\mathrm{H})$, damaging winds $(\mathrm{W})$, and model grid boxes with at least five lightning occurrences (L). Parameter abbreviations are defined in the text.

\begin{tabular}{|c|c|c|c|c|c|c|c|}
\hline Parameter & $\begin{array}{l}\text { Report } \\
\text { type }\end{array}$ & 25 & 50 & 75 & TS & OPSS & Threshold \\
\hline \multirow{4}{*}{ WINDINF } & $\mathrm{T}$ & 10.5 & 15.6 & 20.3 & 40.3 & 0.506 & 11.6 \\
\hline & $\mathrm{H}$ & 5.6 & 10.3 & 14.8 & 41.4 & 0.251 & 8.5 \\
\hline & W & 6.6 & 10.6 & 14.7 & 51.7 & 0.286 & 8.0 \\
\hline & $\mathrm{L}$ & 2.8 & 6.3 & 10.7 & & & \\
\hline \multirow{4}{*}{ WIND0KM } & $\mathrm{T}$ & 5.5 & 8.1 & 11.2 & 21.2 & 0.276 & 6.4 \\
\hline & $\mathrm{H}$ & 3.9 & 6.1 & 8.8 & 14.1 & 0.069 & 5.5 \\
\hline & W & 4.0 & 6.0 & 8.6 & 12.9 & 0.073 & 4.7 \\
\hline & $\mathrm{L}$ & 3.4 & 5.5 & 8.1 & & & \\
\hline \multirow{4}{*}{ WIND1KM } & $\mathrm{T}$ & 10.7 & 15.1 & 19.4 & 34.1 & 0.454 & 11.5 \\
\hline & $\mathrm{H}$ & 6.0 & 9.5 & 14.0 & 20.5 & 0.152 & 7.4 \\
\hline & W & 7.1 & 10.4 & 15.0 & 40.6 & 0.224 & 7.4 \\
\hline & $\mathrm{L}$ & 4.5 & 7.5 & 11.9 & & & \\
\hline \multirow{4}{*}{ WIND2KM } & $\mathrm{T}$ & 12.8 & 17.1 & 20.6 & 38.6 & 0.514 & 14.4 \\
\hline & $\mathrm{H}$ & 8.0 & 11.7 & 16.1 & 35.7 & 0.228 & 8.4 \\
\hline & $\mathrm{W}$ & 8.2 & 12.0 & 16.2 & 48.1 & 0.245 & 9.2 \\
\hline & $\mathrm{L}$ & 5.0 & 8.4 & 12.8 & & & \\
\hline \multirow{4}{*}{ WIND3KM } & $\mathrm{T}$ & 14.2 & 18.7 & 23.3 & 40.7 & 0.513 & 12.9 \\
\hline & $\mathrm{H}$ & 10.1 & 14.1 & 18.7 & 50.3 & 0.290 & 11.3 \\
\hline & W & 9.3 & 12.9 & 17.6 & 46.9 & 0.239 & 8.9 \\
\hline & $\mathrm{L}$ & 5.8 & 9.5 & 14.3 & & & \\
\hline \multirow{4}{*}{ WIND4KM } & $\mathrm{T}$ & 16.0 & 20.7 & 27.0 & 42.7 & 0.518 & 14.8 \\
\hline & $\mathrm{H}$ & 12.1 & 16.6 & 21.3 & 59.0 & 0.329 & 11.9 \\
\hline & W & 10.3 & 14.4 & 19.4 & 46.0 & 0.242 & 9.9 \\
\hline & $\mathrm{L}$ & 6.3 & 10.5 & 16.0 & & & \\
\hline \multirow{4}{*}{ WIND5KM } & $\mathrm{T}$ & 17.9 & 23.6 & 30.4 & 44.6 & 0.543 & 15.8 \\
\hline & $\mathrm{H}$ & 13.6 & 18.5 & 23.6 & 63.5 & 0.354 & 13.5 \\
\hline & W & 11.1 & 15.4 & 21.0 & 44.0 & 0.236 & 10.4 \\
\hline & $\mathrm{L}$ & 6.7 & 11.5 & 17.4 & & & \\
\hline \multirow{4}{*}{ WIND6KM } & $\mathrm{T}$ & 19.1 & 25.8 & 33.3 & 44.4 & 0.532 & 17.0 \\
\hline & $\mathrm{H}$ & 15.2 & 19.9 & 26.7 & 65.1 & 0.366 & 15.1 \\
\hline & W & 11.9 & 16.6 & 22.8 & 43.0 & 0.230 & 10.2 \\
\hline & $\mathrm{L}$ & 7.2 & 12.5 & 18.8 & & & \\
\hline \multirow{4}{*}{ WIND7KM } & $\mathrm{T}$ & 20.8 & 27.6 & 36.2 & 42.9 & 0.517 & 21.2 \\
\hline & $\mathrm{H}$ & 16.0 & 21.7 & 29.3 & 64.4 & 0.348 & 15.8 \\
\hline & W & 12.8 & 17.4 & 24.8 & 39.6 & 0.230 & 11.5 \\
\hline & $\mathrm{L}$ & 7.6 & 13.6 & 20.4 & & & \\
\hline
\end{tabular}

threshold of WIND6KM $=15.1$, and for tornadoes (0.543) using a threshold of WIND5KM $=15.8$. However, the ground-relative winds from 2 to $6 \mathrm{~km}$ AGL have similar scores (Table 1), indicating that strong wind fields throughout the lower/middle troposphere are generally favorable for all types of severe weather.

Storm-relative helicity parameters are also discriminatory for all types of severe weather compared with lightning points (Table 2), with $T$ scores and OPSS values similar to, but slightly less than, the most discrimi- 
TABLE 2. Same as in Table 1 but for storm-relative helicities.

\begin{tabular}{lcrrrrrr}
\hline \hline Parameter & $\begin{array}{c}\text { Report } \\
\text { type }\end{array}$ & 25 & 50 & 75 & TS & OPSS & Threshold \\
\hline \multirow{5}{*}{ SRHEFF } & T & 76 & 194 & 322 & 42.7 & 0.459 & 107 \\
& H & 21 & 100 & 209 & 53.3 & 0.275 & 60 \\
& W & 21 & 85 & 183 & 43.6 & 0.253 & 49 \\
& L & 0 & 26 & 98 & & & \\
& T & 104 & 228 & 316 & 30.2 & 0.439 & 131 \\
SRH01KM & H & 52 & 111 & 217 & 30.0 & 0.197 & 80 \\
& W & 51 & 102 & 194 & 23.9 & 0.179 & 55 \\
& L & 24 & 65 & 142 & & & \\
& T & 182 & 316 & 440 & 33.3 & 0.472 & 167 \\
SRH03KM & H & 110 & 197 & 325 & 42.7 & 0.279 & 119 \\
& W & 87 & 153 & 274 & 25.9 & 0.192 & 100 \\
& L & 45 & 102 & 208 & & & \\
\hline
\end{tabular}

natory ground-relative wind parameters. However, for surface-based vertical wind shear parameters (Table 3), the SHR02KM $T$ score for damaging wind versus lightning points is 29.7 , compared with 48.1 for WIND2KM, and SHRINF for damaging winds has a $T$ score of 43.3, compared with the WINDINF $T$ score of 51.7; so, it seems that lower-tropospheric ground-relative winds are more discriminatory than low-level wind shear for damaging winds (this is not the case for hail and tornadoes). For shear layers based farther aloft (Table 4), most damaging wind points are similar to lightning points, implying that the shear near the surface is most important for damaging winds. However, SHRCLD has a $T$ score of 38.2, and an OPSS of 0.204 (using a threshold of 8.6) for damaging winds, possibly indicating that systems producing damaging winds require some shear in the cloud-bearing layer so that precipitation may be removed from the updraft region and outflow does not cause convective dissipation by cutting off new updrafts. SHRCLD OPSS values for tornadoes $(0.525$ using a threshold of 13.2) and for hail (0.311 using a threshold of 10.8) indicate that shear in the cloudbearing layer may be even more important for other forms of severe weather.

These wind velocity, wind shear, and storm-relative helicity data suggest that damaging wind occurrence is dependent on strong wind fields in the lowest 5-6 km AGL, and may be most dependent on strong groundrelative winds near the top of the unstable inflow layer. Strong wind shear throughout the troposphere allows convection to organize into long-lived, intense systems, by removing precipitation from the updraft region. Strong wind fields in the lowest few kilometers are favorable specifically for damaging winds in several ways. The first is that convectively driven downdrafts can transfer high-momentum air to the surface. The second
TABLE 3. Same as in Table 1 but for shear layers based near the surface.

\begin{tabular}{lcrrrrrr}
\hline \hline \multirow{5}{*}{ Parameter } & $\begin{array}{c}\text { Report } \\
\text { type }\end{array}$ & 25 & 50 & 75 & TS & OPSS & Threshold \\
\hline & T & 8.5 & 13.3 & 17.4 & 38.3 & 0.463 & 9.8 \\
SHRINF & H & 5.1 & 9.0 & 13.6 & 49.0 & 0.248 & 7.8 \\
& W & 5.3 & 8.6 & 12.6 & 43.3 & 0.238 & 6.5 \\
& L & 2.8 & 5.6 & 9.9 & & & \\
& T & 7.1 & 10.7 & 13.8 & 27.6 & 0.218 & 8.8 \\
SHR01KM & H & 4.1 & 6.9 & 10.5 & 20.5 & 0.097 & 8.9 \\
& W & 4.2 & 6.9 & 10.6 & 24.1 & 0.090 & 8.3 \\
& L & 3.3 & 5.5 & 8.9 & & & \\
& T & 11.4 & 15.4 & 18.7 & 33.6 & 0.471 & 12.5 \\
SHR02KM & H & 7.5 & 11.3 & 15.3 & 39.3 & 0.223 & 8.1 \\
& W & 7.0 & 10.1 & 14.2 & 29.7 & 0.181 & 7.1 \\
& L & 4.8 & 8.0 & 12.2 & & & \\
& T & 16.5 & 20.5 & 25.2 & 37.9 & 0.524 & 16.0 \\
SHR04KM & H & 12.4 & 16.9 & 21.9 & 60.0 & 0.345 & 13.0 \\
& W & 9.4 & 13.4 & 18.7 & 30.2 & 0.197 & 8.9 \\
& L & 6.2 & 10.5 & 16.3 & & & \\
& T & 20.2 & 26.8 & 31.6 & 41.6 & 0.518 & 18.2 \\
& H & 14.9 & 21.0 & 27.7 & 65.5 & 0.352 & 15.0 \\
SHR06KM & W & 10.5 & 16.0 & 22.6 & 29.4 & 0.171 & 10.3 \\
& L & 7.0 & 12.4 & 19.5 & & & \\
\hline & & & & & & & \\
\hline
\end{tabular}

is that fast environmental wind fields lead to rapid storm motion and fast-moving gust fronts (and hence strong ground-relative winds) in an MCS (Evans and Doswell 2001; Corfidi 2003). The third is that fast environmental wind aloft entails high values of vertical wind shear, which may favor longer-lived MCSs (Rotunno et al. 1988). Since the wind velocities at the sur-

TABLE 4. Same as in Table 1 but for shear layers based aloft.

\begin{tabular}{lcrrrrrr}
\hline \hline \multirow{2}{*}{ Parameter } & $\begin{array}{c}\text { Report } \\
\text { type }\end{array}$ & 25 & 50 & \multicolumn{1}{c}{75} & TS & OPSS & Threshold \\
\hline \multirow{5}{*}{ SHRCLD } & T & 13.3 & 20.9 & 27.3 & 48.9 & 0.525 & 13.2 \\
& H & 7.8 & 13.7 & 20.3 & 62.3 & 0.311 & 10.8 \\
& W & 6.0 & 10.8 & 16.7 & 38.2 & 0.204 & 8.6 \\
& $\mathrm{~L}$ & 3.5 & 7.1 & 12.5 & & & \\
& $\mathrm{~T}$ & 6.8 & 9.8 & 13.3 & 23.2 & 0.343 & 7.6 \\
SHR13KM & $\mathrm{H}$ & 6.2 & 9.2 & 12.7 & 50.2 & 0.293 & 7.3 \\
& $\mathrm{~W}$ & 4.8 & 7.3 & 10.6 & 20.8 & 0.138 & 4.7 \\
& $\mathrm{~L}$ & 3.5 & 5.9 & 9.3 & & & \\
& $\mathrm{~T}$ & 9.0 & 13.8 & 17.2 & 31.6 & 0.427 & 11.6 \\
SHR26KM & $\mathrm{H}$ & 7.3 & 11.2 & 16.0 & 57.9 & 0.300 & 7.9 \\
& $\mathrm{~W}$ & 4.5 & 7.5 & 11.9 & 12.8 & 0.062 & 7.5 \\
& $\mathrm{~L}$ & 4.0 & 6.7 & 10.7 & & & \\
& $\mathrm{~T}$ & 4.9 & 8.5 & 12.4 & 16.6 & 0.220 & 8.5 \\
SHR58KM & $\mathrm{H}$ & 4.8 & 7.5 & 11.1 & 28.3 & 0.139 & 6.3 \\
& $\mathrm{~W}$ & 4.2 & 6.6 & 9.8 & 12.0 & 0.065 & 5.6 \\
& $\mathrm{~L}$ & 3.7 & 6.0 & 9.1 & & & \\
\hline
\end{tabular}


TABLE 5. Same as in Table 1 but for CAPE parameters and MLLCL.

\begin{tabular}{|c|c|c|c|c|c|c|c|}
\hline Parameter & $\begin{array}{l}\text { Report } \\
\text { type }\end{array}$ & 25 & 50 & 75 & TS & OPSS & Threshold \\
\hline \multirow{4}{*}{ MLCAPE } & $\mathrm{T}$ & 277 & 1150 & 2394 & 9.3 & 0.115 & 2296 \\
\hline & $\mathrm{H}$ & 294 & 1117 & 2199 & 17.3 & 0.087 & 1071 \\
\hline & W & 371 & 1145 & 2131 & 19.2 & 0.100 & 562 \\
\hline & $\mathrm{L}$ & 154 & 839 & 1794 & & & \\
\hline \multirow{4}{*}{ MUCAPE } & $\mathrm{T}$ & 981 & 2101 & 3236 & 13.6 & 0.200 & 2446 \\
\hline & $\mathrm{H}$ & 981 & 1855 & 2925 & 24.3 & 0.129 & 1436 \\
\hline & W & 1021 & 1903 & 2952 & 27.6 & 0.146 & 1430 \\
\hline & $\mathrm{L}$ & 617 & 1418 & 2446 & & & \\
\hline \multirow{4}{*}{ DCAPE } & $\mathrm{T}$ & 634 & 823 & 1099 & 8.7 & 0.163 & 667 \\
\hline & $\mathrm{H}$ & 655 & 889 & 1147 & 31.0 & 0.179 & 694 \\
\hline & W & 624 & 878 & 1137 & 32.6 & 0.155 & 811 \\
\hline & L & 481 & 727 & 989 & & & \\
\hline \multirow{4}{*}{ MLLCL } & $\mathrm{T}$ & 485 & 737 & 1074 & -11.2 & 0.146 & 1235 \\
\hline & $\mathrm{H}$ & 636 & 978 & 1437 & -0.7 & 0.069 & 868 \\
\hline & W & 607 & 914 & 1256 & -9.3 & 0.041 & 627 \\
\hline & $\mathrm{L}$ & 578 & 876 & 1378 & & & \\
\hline
\end{tabular}

face for damaging wind points are similar to those for lightning points, stronger flow aloft for the damaging wind points necessarily implies greater shear as well. The ground-relative winds are statistically more discriminatory, but whether the shear, helicity, or the ground-relative wind velocity is more important physically cannot be definitively determined from these data.

\section{b. Thermodynamic parameters}

The CAPE parameters do not discriminate between damaging wind points and lightning points as well as the wind-related parameters. The three severe modes generally have similar amounts of MUCAPE and MLCAPE to one another (Table 5), but lightning values for those three parameters are also fairly high, so that the $T$ scores and OPSS values are smaller than for the wind-related parameters (cf. Tables 1-4). CAPE is necessary for deep moist convection to occur; however, these data suggest that only a minimal amount is needed to generate severe weather of all types. With regard to severe winds it may be that, once CAPE is sufficient for deep convection, damaging winds can occur via downdrafts that transport high-momentum air downward from aloft, or through mesoscale pressure perturbations in the surface outflow.

DCAPE is somewhat discriminatory between points with damaging winds and lightning, with the highest OPSS value ( 0.155 using a threshold of 811$)$ and $T$ score (32.6) of all parameters tested save the wind-related ones. MLLCL is not very discriminatory for damaging
TABLE 6. Same as in Table 1 but for lapse rates.

\begin{tabular}{cccccccc}
\hline \hline \multirow{2}{*}{ Parameter } & $\begin{array}{c}\text { Report } \\
\text { type }\end{array}$ & 25 & 50 & 75 & \multicolumn{1}{c}{ TS } & OPSS & Threshold \\
\hline \multirow{5}{*}{ LAPSE01KM } & $\mathrm{T}$ & 4.0 & 5.5 & 6.6 & -1.1 & 0.143 & 6.7 \\
& $\mathrm{H}$ & 3.9 & 6.0 & 7.2 & -0.5 & 0.014 & 5.4 \\
& $\mathrm{~W}$ & 3.8 & 5.8 & 7.2 & 1.4 & 0.023 & 7.7 \\
& $\mathrm{~L}$ & 3.9 & 5.9 & 7.3 & & & \\
& $\mathrm{~T}$ & 4.8 & 5.7 & 6.4 & -5.7 & 0.181 & 6.4 \\
LAPSE02KM & $\mathrm{H}$ & 4.9 & 6.2 & 7.1 & -2.3 & 0.022 & 6.1 \\
& $\mathrm{~W}$ & 4.8 & 5.9 & 6.9 & -5.7 & 0.058 & 7.3 \\
& $\mathrm{~L}$ & 4.9 & 6.1 & 7.2 & & & \\
& $\mathrm{~T}$ & 5.1 & 6.1 & 7.0 & -10.0 & 0.130 & 6.7 \\
LAPSE12KM & $\mathrm{H}$ & 5.4 & 6.6 & 7.7 & -4.8 & 0.020 & 6.6 \\
& $\mathrm{~W}$ & 5.3 & 6.3 & 7.3 & -15.4 & 0.073 & 7.3 \\
& $\mathrm{~L}$ & 5.5 & 6.5 & 7.8 & & & \\
& $\mathrm{~T}$ & 5.8 & 6.3 & 6.9 & -4.1 & 0.001 & 2.8 \\
LAPSE14KM & $\mathrm{H}$ & 6.2 & 6.8 & 7.4 & 23.1 & 0.201 & 6.3 \\
& $\mathrm{~W}$ & 6.0 & 6.4 & 7.0 & -0.7 & 0.076 & 6.0 \\
& $\mathrm{~L}$ & 5.8 & 6.3 & 7.2 & & & \\
& $\mathrm{~T}$ & 6.2 & 6.9 & 7.8 & 15.6 & 0.163 & 6.0 \\
& $\mathrm{H}$ & 6.4 & 7.1 & 7.8 & 53.8 & 0.203 & 5.9 \\
LAPSE35KM & $\mathrm{W}$ & 5.9 & 6.6 & 7.4 & 17.2 & 0.093 & 6.4 \\
& $\mathrm{~L}$ & 5.7 & 6.3 & 7.1 & & & \\
\hline
\end{tabular}

winds (Table 5), even though high MLLCL heights could promote subcloud evaporative cooling and stronger downdrafts. However, MLLCL does weakly discriminate between tornado points and lightning points. Markowski (2002) suggested that rear-flank downdrafts that are not excessively cold are more favorable for tornado development, and that low MLLCL heights keep those downdrafts warm by decreasing the time that subcloud evaporative cooling can take place.

Lapse rate parameters are not very discriminatory for damaging winds (Table 6), as no damaging wind OPSS values are above 0.100. Steep lapse rates are hypothesized to be important for damaging winds (Wakimoto 1985; Srivastava 1985; Atkins and Wakimoto 1991) because negatively buoyant downdrafts are suppressed when lapse rates are stable. These results suggest that processes unrelated to lapse rates may have been more important causes of widespread damaging winds, or that perhaps RUC model soundings inaccurately portray temperature fields in the boundary layer. Lapse rate parameters are somewhat useful in discriminating between hail and lightning points. For example, LAPSE14KM has an OPSS of 0.201 using a threshold of 6.3 and LAPSE35KM has an OPSS of 0.203 using a threshold of 5.9. The same is true for tornado and lightning points: LAPSE02KM has an OPSS of 0.181 using a threshold of 6.4 (note that lightning points had higher LAPSE02KM, not tornado 
TABLE 7. Same as in Table 1 but for CIN parameters.

\begin{tabular}{lcrrrrrr}
\hline & $\begin{array}{c}\text { Report } \\
\text { Parameter }\end{array}$ & & & & & & \\
& type & 25 & 50 & 75 & TS & OPSS & Threshold \\
& $\mathrm{T}$ & 12 & 40 & 103 & -1.4 & 0.109 & 4 \\
MLCIN & $\mathrm{H}$ & 17 & 51 & 118 & 7.5 & 0.109 & 16 \\
& $\mathrm{~W}$ & 16 & 49 & 116 & 10.1 & 0.128 & 11 \\
& $\mathrm{~L}$ & 9 & 37 & 94 & & & \\
MUCIN & $\mathrm{T}$ & 9 & 27 & 54 & 5.8 & 0.132 & 11 \\
& $\mathrm{H}$ & 6 & 21 & 49 & 8.2 & 0.066 & 16 \\
& $\mathrm{~W}$ & 5 & 19 & 47 & 12.5 & 0.044 & 62 \\
& $\mathrm{~L}$ & 5 & 16 & 42 & & & \\
\hline
\end{tabular}

points) and LAPSE35KM has an OPSS of 0.163 using a threshold of 6.0.

MLCIN and MUCIN (Table 7) show surprisingly little discrimination among the three severe modes and ordinary convection. In particular, it appears that, once deep moist convection occurs, CIN does not significantly inhibit the production of severe surface winds. Perhaps this reflects unstable parcels with high CIN being dynamically forced a few kilometers upward into convection, loaded with precipitation, and then buoyantly forced back to the surface in an "up-down" trajectory as described by Knupp (1987).

Examining relative humidity in different atmospheric layers, damaging wind $T$ scores and OPSS values (Table 8 ) indicate some discrimination between drier damaging wind points and moister lightning points (OPSS as high as 0.131 using a threshold of 49.6 for MINRH24KM). As with steep lapse rates, numerous studies (e.g., Knupp 1987; Kingsmill and Wakimoto 1991) link dry air entrainment in the midlevels to downdraft initiation and damaging winds, but other processes like precipitation loading and melting could also initiate a downdraft, and compressional warming within a downward-rushing parcel could provide the lowered relative humidity needed to allow evaporational cooling and the generation of negative buoyancy regardless of the moisture content in the ambient environment. In short, other parameters seem to be more useful.

\section{c. A composite parameter}

Because multiple parameters are discriminatory when forecasting severe convective winds, a composite parameter (DMGWIND) was devised that combines them in order to give one forecast of damaging winds in a given environment when convection is anticipated. There are numerous shortfalls for this type of method. The first is the lack of complete understanding about how the environment generates damaging thunderstorm winds. There is a hypothesis for how each dis-
TABLE 8. Same as in Table 1 but for relative humidities.

\begin{tabular}{|c|c|c|c|c|c|c|c|}
\hline Parameter & $\begin{array}{l}\text { Report } \\
\text { type }\end{array}$ & 25 & 50 & 75 & TS & OPSS & Threshold \\
\hline \multirow{4}{*}{ MINRH24KM } & $\mathrm{T}$ & 20.6 & 37.3 & 51.7 & -22.4 & 0.290 & 48.8 \\
\hline & $\mathrm{H}$ & 26.9 & 41.0 & 55.8 & -45.3 & 0.228 & 46.0 \\
\hline & $\mathrm{W}$ & 32.7 & 46.1 & 61.9 & -24.0 & 0.131 & 49.6 \\
\hline & $\mathrm{L}$ & 38.7 & 53.2 & 67.9 & & & \\
\hline \multirow{4}{*}{ MINRH26KM } & $\mathrm{T}$ & 15.9 & 27.8 & 44.1 & -16.3 & 0.232 & 26.5 \\
\hline & $\mathrm{H}$ & 17.0 & 27.6 & 41.4 & -45.7 & 0.239 & 35.1 \\
\hline & W & 22.3 & 34.2 & 47.8 & -23.6 & 0.123 & 40.9 \\
\hline & $\mathrm{L}$ & 26.0 & 40.1 & 55.7 & & & \\
\hline \multirow{4}{*}{ MINRH46KM } & $\mathrm{T}$ & 17.3 & 32.0 & 51.2 & -14.5 & 0.223 & 26.5 \\
\hline & $\mathrm{H}$ & 17.9 & 31.2 & 47.6 & -41.7 & 0.215 & 37.0 \\
\hline & W & 23.9 & 39.0 & 54.0 & -20.3 & 0.112 & 52.9 \\
\hline & $\mathrm{L}$ & 27.8 & 44.5 & 62.1 & & & \\
\hline
\end{tabular}

criminatory parameter contributes to the formation of damaging winds, but a parameter that appears to be significant may also simply be well correlated to another physically relevant parameter while not itself being of much physical importance. Another problem is that storms may generate damaging winds in different and numerous ways (convectively generated horizontal pressure gradients, downdrafts caused by several processes, downward momentum transfer, combinations of the three) so that not every parameter is important in every situation, and not every damaging wind environment can be diagnosed by looking at sounding parameters. Nonetheless, parameters that appear to discriminate between ordinary convection and convection that produces damaging winds over a very large number of cases may be combined into one parameter that has forecast skill.

Previous severe weather indices have relied on adding parameters together [total totals, Severe Weather Threat or SWEAT, and K index] or multiplying and dividing them [e.g., the Storm Prediction Center (SPC) supercell and significant tornado predictors (Thompson et al. 2003), energy-helicity index, and bulk Richardson number]. The SPC supercell and significant tornado predictors normalize each input parameter by a threshold value before they are multiplied together. This method assumes that a change in one parameter in the index makes the environment proportionally more or less favorable for the type of weather the index is attempting to predict, which may not necessarily be true.

DMGWIND was developed using the same normalization and multiplication technique described by Thompson et al. (2003). Only those discriminatory parameters clearly related to physical damaging wind mechanisms were selected. As outlined in section 1, downdraft strength, cold pool gust fronts, and orga- 
TABLe 9. Same as Table 1 but for DMGWIND.

\begin{tabular}{cccccccc}
\hline \hline \multirow{2}{*}{ Parameter } & $\begin{array}{c}\text { Report } \\
\text { type }\end{array}$ & 25 & 50 & 75 & TS & OPSS & Threshold \\
\hline \multirow{4}{*}{ DMGWIND } & T & 1.0 & 2.0 & 3.0 & 39.9 & 0.453 & 1.4 \\
& $\mathrm{H}$ & 0.7 & 1.4 & 2.2 & 54.5 & 0.286 & 1.1 \\
& $\mathrm{~W}$ & 0.8 & 1.4 & 2.2 & 56.2 & 0.307 & 1.0 \\
& $\mathrm{~L}$ & 0.3 & 0.7 & 1.3 & & & \\
\hline
\end{tabular}

nized convective system strength and speed can all affect the existence and extent of damaging winds. Because there are good physical reasons to expect WINDINF to be related to damaging surface winds (outlined earlier), and because WINDINF discriminates well between observed damaging wind occurrence and ordinary convection because of its high OPSS value and $T$ score (Table 1), it was chosen to be one of the parameters. In addition to having the highest OPSS value and $T$ score among the thermodynamic parameters (Table 5), DCAPE is one way to estimate downdraft potential energy and potential cold pool strength, so it was chosen as the second parameter. Both parameters are normalized by their approximate OPSS threshold value and then multiplied together:

$$
\text { DMGWIND }=\frac{\text { WINDINF }}{8.0} \times \frac{\text { DCAPE }}{800.0} .
$$

The composite parameter is dimensionless and does not have physical meaning. However, since it combines parameters that are good discriminators of damaging wind environments, DMGWIND is a better discriminator between damaging wind points and lightning points (Table 9) with an OPSS value of 0.307 (using a threshold value of 1.0).

It is worth noting that DMGWIND has a fairly high OPSS value when comparing hail points with lightning points (0.286 using a threshold of 1.1), and has a much higher OPSS when assessing the tornado points $(0.453$ using a threshold of 1.4). Because DMGWIND incorporates two parameters that are also discriminatory for hail and tornadoes, this is not surprising. Indeed, damaging wind points only rarely have the highest OPSS value among the severe modes for any studied parameter, and even then it is only slightly higher. This is an indication that sounding parameters alone do not distinguish between environments that produce only damaging winds versus environments that produce all three modes. However, there are many parameters (SHRCLD, LAPSE35KM, WIND6KM, etc.) for which tornadoes and hail have much higher OPSS values, and therefore parameters such as these could be used to distinguish hail and tornado environments from both damaging wind environments and ordinary convective environments.

\section{d. Case studies}

Following the above discussion, it should be emphasized that complex convective system evolution does not lend itself to easy prognosis with sounding parameters, and this evolution likely plays a key role in damaging wind occurrence. Because operational forecasters must have a complementary situational awareness of the regimes in which other factors may enhance or hinder the production of severe winds, 11 case studies were examined, including both widespread damaging wind events and events where severe weather or convection occurred but damaging winds did not. These cases were chosen because they presented significant operational forecasting challenges in real time.

\section{1) Overview of COMmonalities}

Although a more extensive case-by-case verification will be needed, a preliminary investigation of 11 cases where convection occurred with DMGWIND above 1.0 revealed two likely failure modes for damaging convective surface winds. First, when a convective line forms that is parallel to WINDINF (occurred in two cases), it tends to remain stationary or move forward very slowly, so that ground-relative gust front winds are weak and damaging winds less frequent. When damaging winds do occur with line-parallel WINDINF, it is possibly because of downdrafts that bring momentum from aloft where winds are already close to severe limits, or from intense individual microbursts. Second, when WINDINF is blowing from warm to cold over a warm front or stationary front (occurred in five cases), the potentially buoyant air parcels flow over the top of stable air, yielding elevated convection and perhaps minimizing penetrative downdrafts and surface cold pool development. These two failure modes appeared to explain a lack of widespread damaging winds in seven of the case studies where sounding parameters alone indicated damaging wind potential.

It is instructive to categorize the cases where damaging winds did occur by whether they were in the warm sector or cold sector of midlatitude cyclones. In warm sector severe wind events (occurred in four cases), convection is typically forced and regenerated by a cold pool gust front, or a strong cold front or trough (Evans and Doswell 2001; Stoelinga et al. 2003), with at least a minimal amount of MLCAPE for surface-based convection, a minimal amount of DCAPE for downdrafts, and with WINDINF vectors oriented at least somewhat perpendicular to the gust front, cold front, or trough 


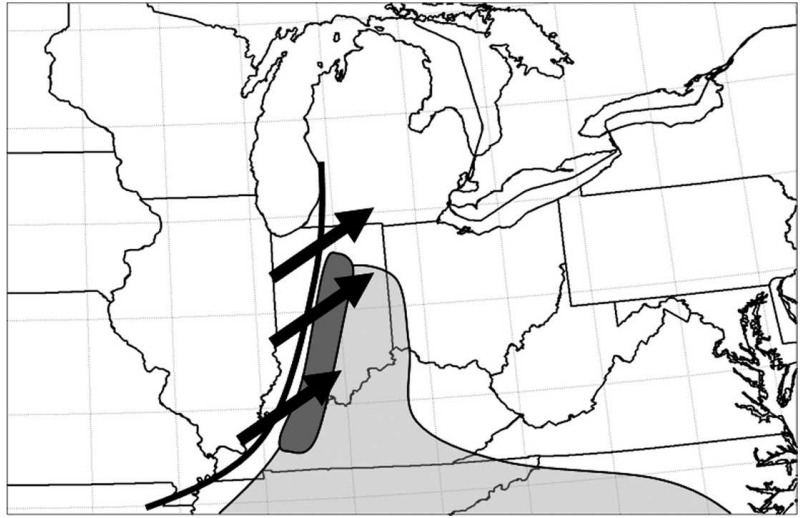

FIG. 1. Conceptual model of the setting for a damaging wind system in the warm sector. Arrows indicate wind direction at the highest positively buoyant level in the surface inflow layer, the solid black line indicates the synoptic frontal position, light shading indicates positive surface-based CAPE, and dark shading indicates strong convection.

(Fig. 1). Buoyancy-generated cold pools need not be strong if large-scale linear forcing mechanisms are intense enough to renew convection, but there must be at least some MLCAPE to maintain a convective relationship between the surface and the stronger winds aloft. WINDINF vectors that are parallel to cold fronts, troughs, or surface outflow boundaries (occurred in two cases) may be a common failure mode for warm sector events (Fig. 2).

Cold sector severe wind events can be initiated by any mechanism on the cold side of a warm front or stationary front (this sector is also known as the "cool" sector to distinguish its typically warmer and moister air from the remaining cold sector behind the cold front), but in order to produce severe winds they must be maintained by a strong surface cold pool whose gust front lifts unstable air into vigorous new updrafts (Fig. 3). Without a large-scale linear forcing mechanism to organize and renew convection, MLCAPE and DCAPE must remain relatively high so that convectively generated precipitation and strong downdrafts can continually reinforce the cold pool. WINDINF vectors that are optimally both parallel to the front and perpendicular to the convective outflow boundary (occurred in two cases) indicate convection may produce widespread damaging wind systems. WINDINF vectors that are perpendicular to the warm/stationary front (occurred in five cases) indicate convection may tend to be elevated above the stable air, which may be a common failure mode for cold sector events (Fig. 4).

With these conceptual models in mind, the following are four representative examples of both wind and nonwind events in both the warm and cold sector settings.

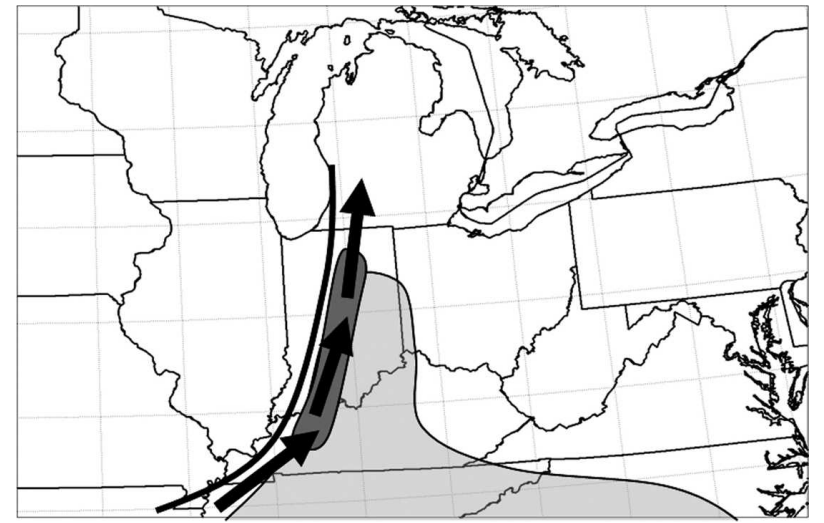

FIG. 2. Same as in Fig. 1 but for a warm sector system that will not produce widespread damaging winds.

\section{2) 11 MAY 2003 WARM SECTOR CASE WITH SEVERE WINDS}

On 10 May 2003 around 1800 UTC, supercellular convection associated with a cold front and a deep low pressure system developed in Oklahoma, Missouri, and Arkansas. By 0300 UTC, convection had also developed to the north of the warm front in Wisconsin and Iowa, and WINDINF was strong, southwesterly, and somewhat perpendicular to the convective line associated with an MCS that had formed in Illinois, Missouri, and Arkansas (Fig. 5). DMGWIND (Fig. 5) was over 2.0 across a large area, indicating damaging winds were possible. This MCS appeared to evolve into a cold-pool-driven system ahead of the cold front, with over 100 damaging wind reports throughout the night concentrated in Kentucky and Tennessee from 0500 to 1300 UTC (Fig. 6). Farther north in Michigan, thunderstorms forming near and to the north of a warm front did not produce any damaging winds,

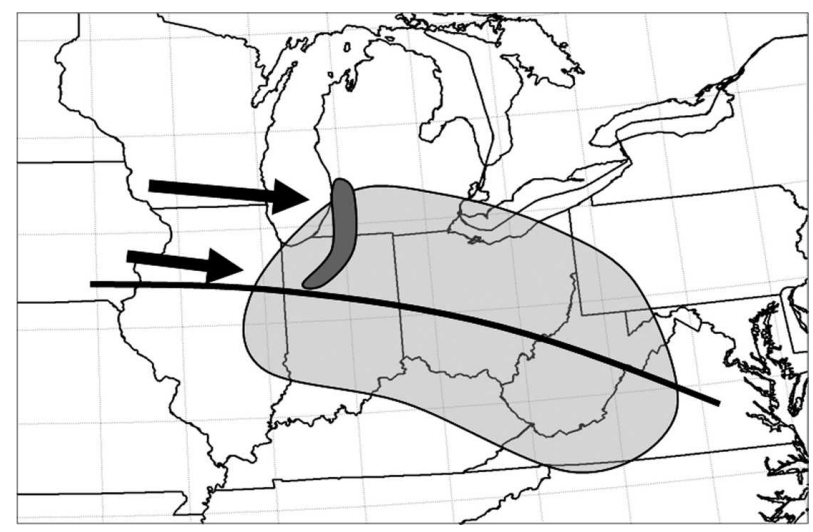

FIG. 3. Same as in Fig. 1 but for a cold sector system that will produce widespread damaging winds. 


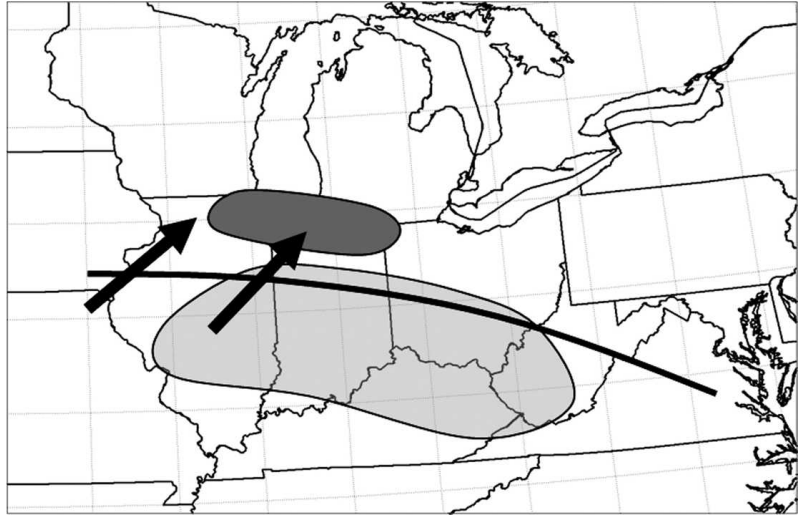

FIG. 4. Same as in Fig. 1 but for a cold sector system that will not produce widespread damaging winds.

despite DMGWIND around 2.0. WINDINF (Fig. 6) was perpendicular to the warm front in Michigan, perhaps leading to elevation of the potentially buoyant parcels above stable air, making damaging winds less likely.

\section{3) 20 APRIL 2003 WARM SECTOR NULL CASE}

From 1800 to 1900 UTC 19 April 2003, convection developed near a low pressure system and cold front in northern Oklahoma and Kansas, and along a dryline extending into southern Oklahoma. By 0000 UTC, su- percells with large hail and tornadoes were occurring along this dryline, while strong convection with large hail continued along the cold front to the north. DMGWIND values around 1.0-2.0 also indicated damaging winds were possible (Fig. 7). WINDINF was parallel to the convection along the cold front and along the dryline so that widespread damaging winds would not be expected in the warm sector conceptual model (i.e., Fig. 2). A few damaging wind reports were received with convection ahead of the cold front, and a few were received with a supercell on the dryline over the next several hours, but no widespread areas of damaging winds were reported. At 0600 UTC, WINDINF was still parallel to the entire convective line (Fig. 8), and no damaging winds were reported. In total, the episode resulted in over 80 large hail reports (up to softball size), and 16 tornado reports, but only 19 reports of wind damage. DMGWIND was above 1.0 over much of the area where convection occurred, but WINDINF was parallel to the convective lines that formed, which, according to the warm sector conceptual model, means damaging winds were less likely.

\section{4) 5 July 2003 COLD SECTOR CASE WITH SEVERE WINDS}

On 5 July 2003 from 0200 to 0300 UTC, warm air advection over a stationary front initiated a band of elevated convection in northwest Iowa. For a few

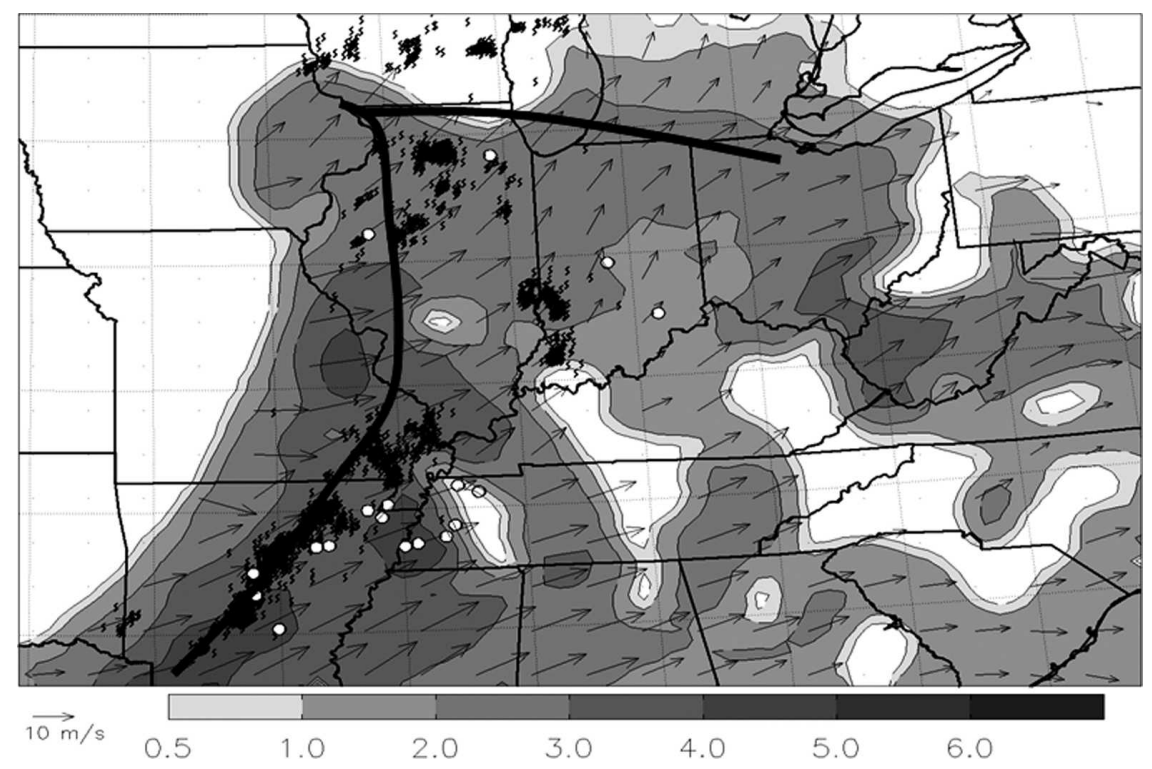

FIG. 5. The RUC analysis of DMGWIND and WINDINF valid at 0300 UTC 11 May 2003. DMGWIND is shaded as shown and WINDINF are vectors scaled as shown. Black zigzag symbols indicate lightning strikes for up to $10 \mathrm{~min}$ after the analysis time. White circles indicate damaging wind reports for up to $3 \mathrm{~h}$ after the analysis time. Heavy black curves indicate positions of synoptic-scale fronts. 


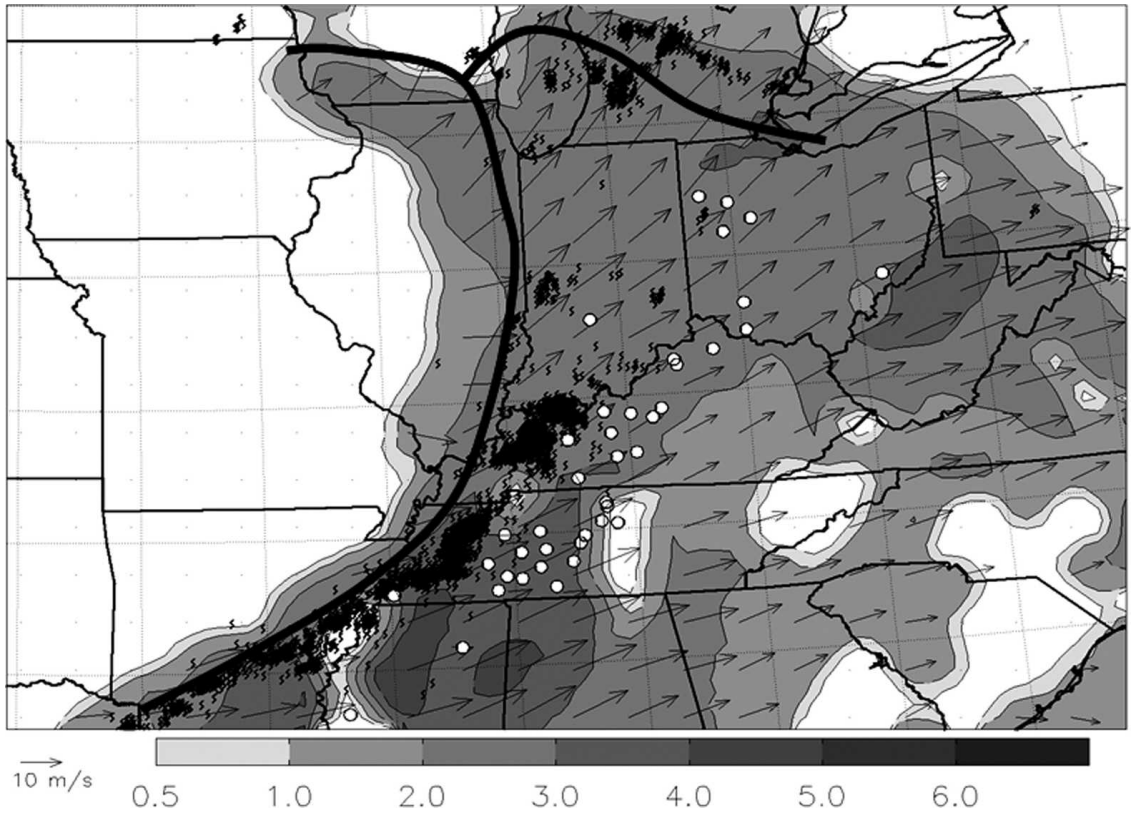

FIG. 6. Same as in Fig. 5 but valid at 0600 UTC 11 May 2003.

hours, this convection produced mainly large hail and heavy rain, and moved slowly southward, remaining north of the surface front. WINDINF was southwesterly and somewhat perpendicular to the boundary where convection began in western Iowa (Fig. 9), supporting parcels overrunning the boundary and overlaying stable air, with damaging winds less likely in the cold sector conceptual model. Between 0500 and 0600, however, the eastern edge of the band became oriented north-south and a bow echo began to form. WINDINF was parallel to the stationary front in central and eastern Iowa (Fig. 9), which conforms to the cold sector model for damaging wind occurrence. It appears that the original convection gradually produced a cold pool near the surface front, and a strong gust front on the eastern edge of the outflow was able to lift unstable

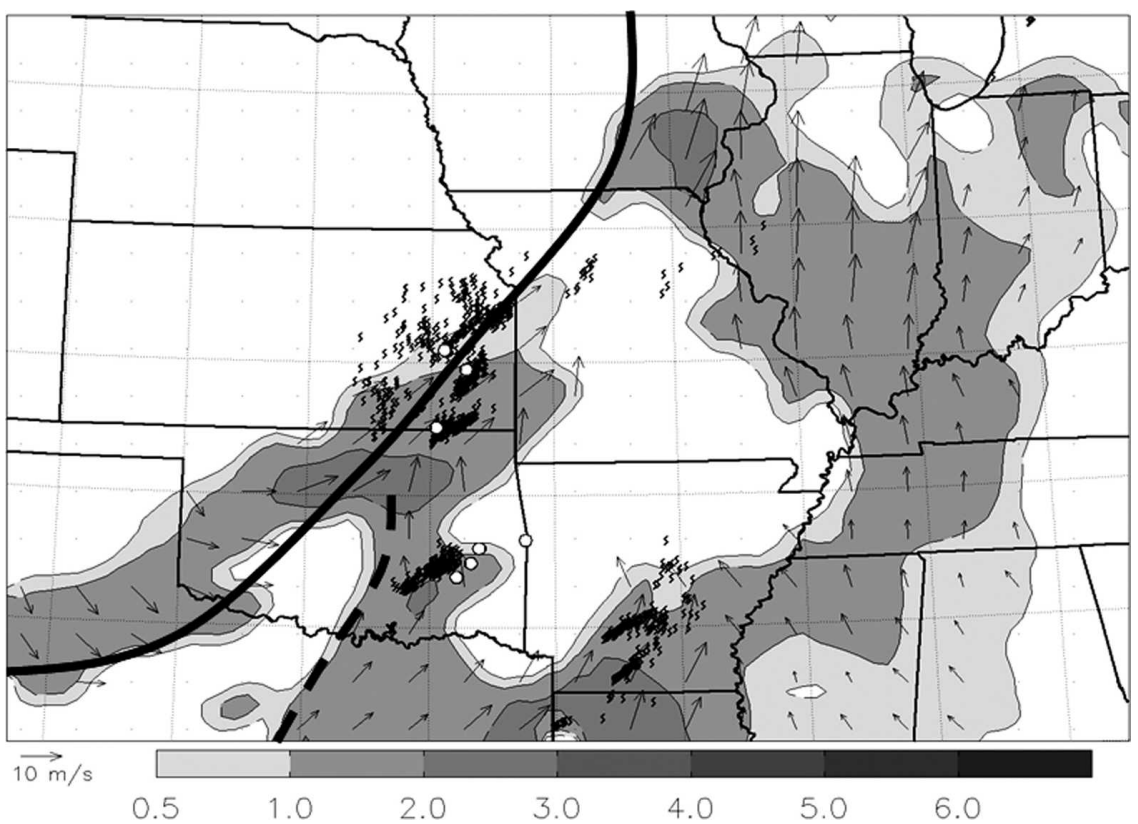

FIG. 7. Same as in Fig. 5 but valid at 0000 UTC 20 Apr 2003. Heavy dashed black curve indicates position of surface dryline. 


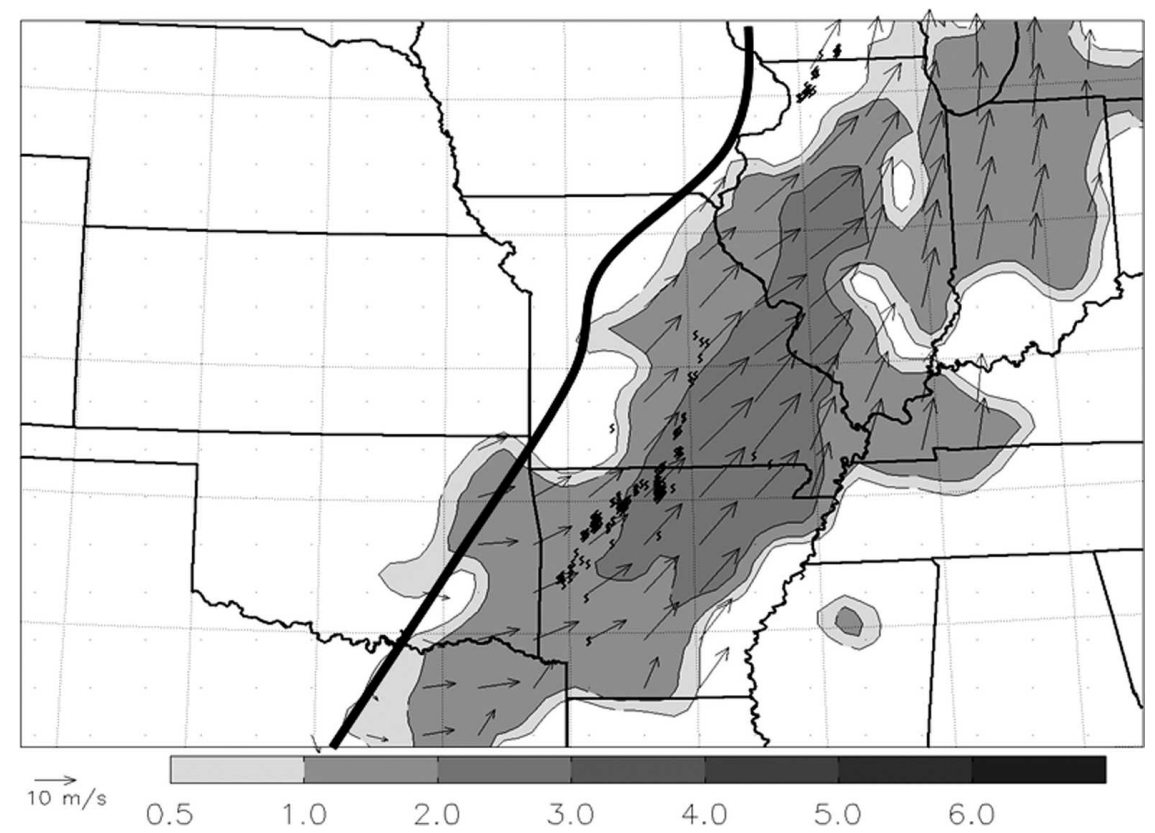

FIG. 8. Same as in Fig. 5 but valid at 0600 UTC 20 Apr 2003.

low-level air into new, surface-based updrafts, because strong westerly SHRINF (Fig. 10) possibly balanced the eastward-moving gust front. As this occurred, DMGWIND was also above 1.0, indicating that damaging winds were possible (Fig. 9). The bow echo moved rapidly eastward into northern Illinois, and continued to produce a concentrated swath of damaging winds with nearly 50 reports received through 1300 UTC.

\section{5) 8 July 2003 COLD SECTOR NULL CASE}

In the early afternoon on 7 July 2003, intense thunderstorms formed in Colorado and Wyoming near a surface trough. By 0000 UTC, a warm front was across

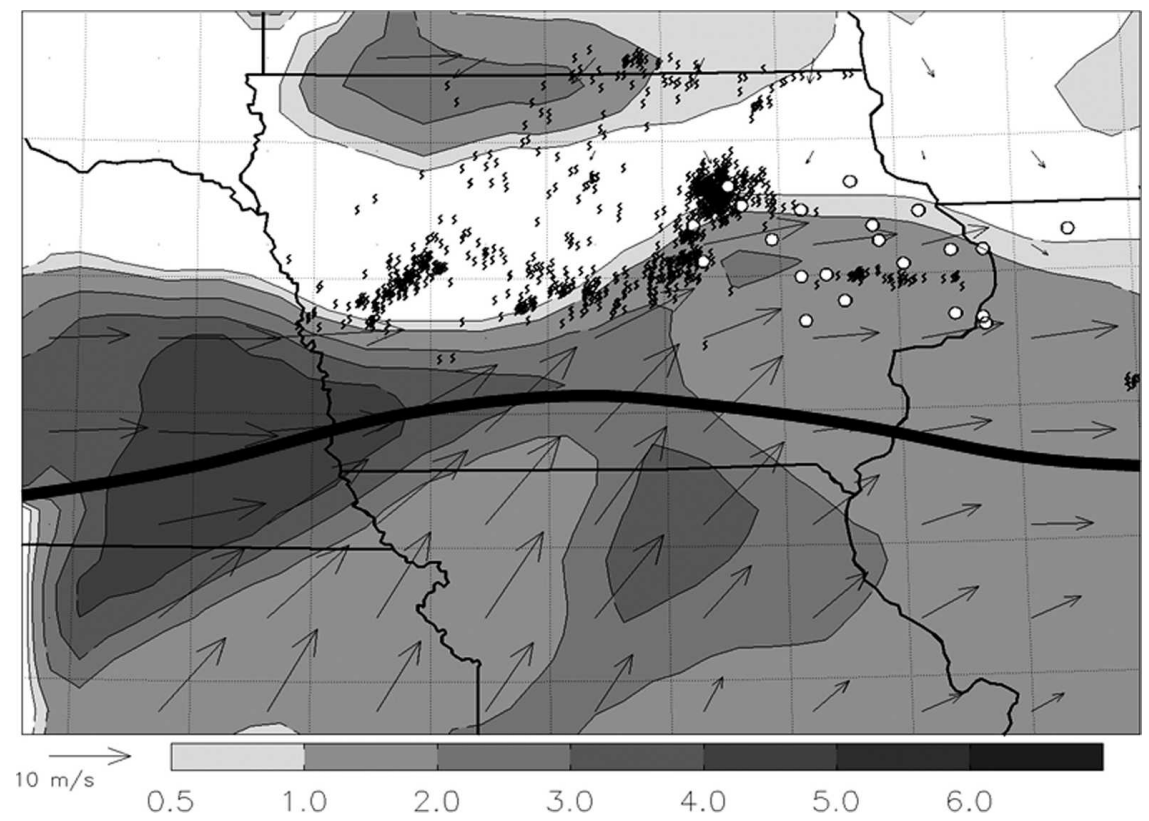

FIG. 9. Same as in Fig. 5 but valid at 0600 UTC 5 Jul 2003. 


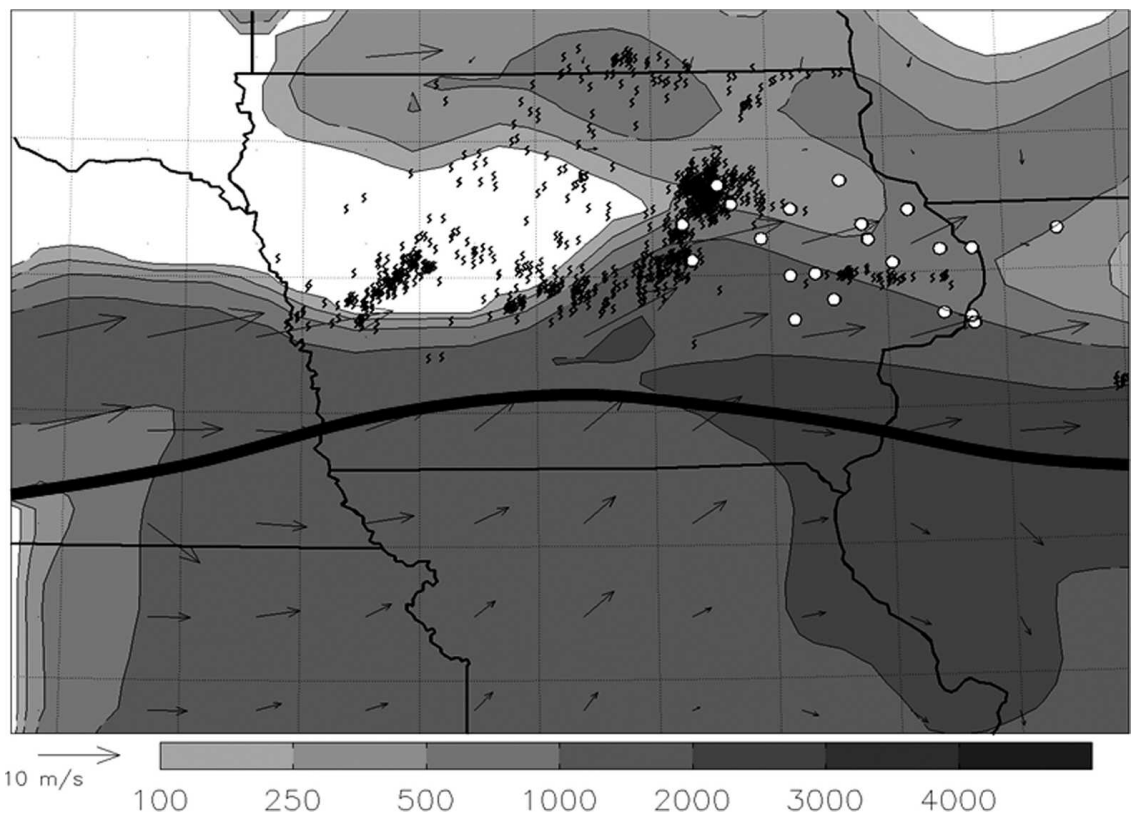

FIG. 10. RUC analysis of MIXCAPE and SHRINF valid at 0600 UTC 5 Jul 2003. MIXCAPE is shaded as shown and SHRINF vectors are scaled as shown. All other symbols are as in Fig. 5.

southern Nebraska with easterly surface flow to its north. DMGWIND values around 2.0 (Fig. 11) indicated that damaging winds were possible to the north of the surface boundary, and from 0100 to 0410 UTC, 15 reports of damaging winds were received from southwestern Nebraska, including one report of a $44 \mathrm{~m} \mathrm{~s}^{-1}$ gust. However, WINDINF was perpendicular to the warm front (Fig. 11), which is hypothesized to be unfavorable for damaging winds in the cold sector model. The initial damaging winds were likely because of the rapid development of a strong cold pool in a high DCAPE environment (Fig. 12), as evidenced by a 6.9$\mathrm{hPa}$ pressure rise and 15-K temperature drop in Sidney, Nebraska, with the passage of the convection. How-

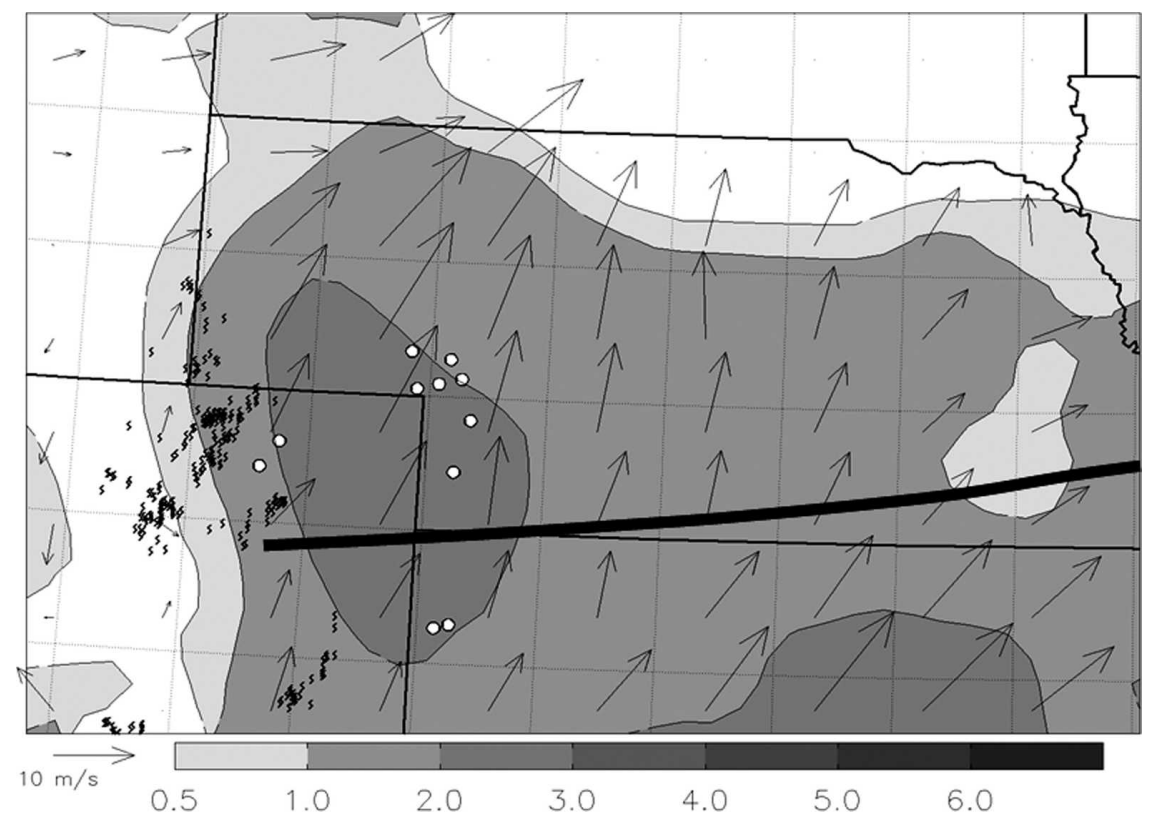

FIG. 11. Same as in Fig. 5 but valid at 0000 UTC 8 Jul 2003. 

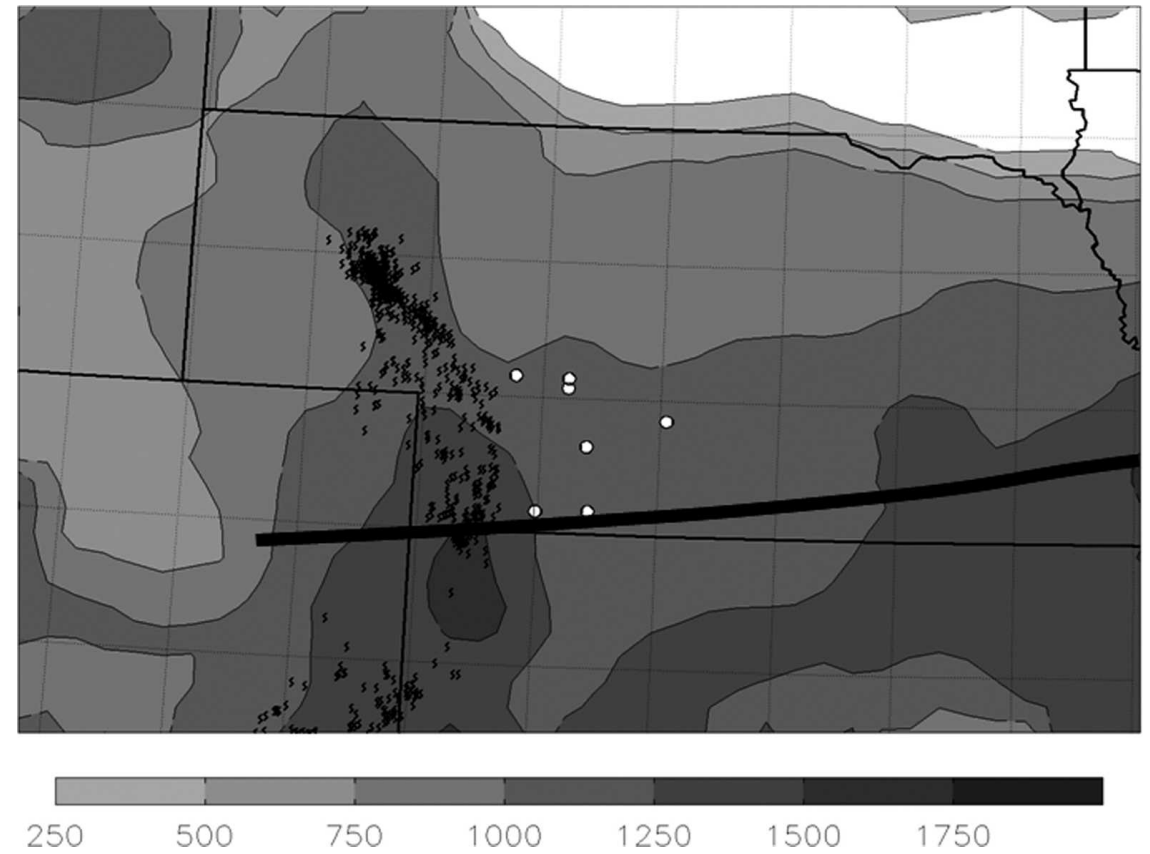

FIG. 12. RUC analysis of DCAPE valid at 0000 UTC 8 Jul 2003. DCAPE is shaded as shown and all other symbols are as in Fig. 5.

ever, despite $2000 \mathrm{~J} \mathrm{~kg}^{-1}$ of MLCAPE (Fig. 13), this system gradually began to weaken and did not produce any damaging winds after 0410 UTC, perhaps because WINDINF was perpendicular to the warm front and parallel to the convective line (Fig. 14). Elevated convection formed well to the north in South Dakota (Fig. 14), as may be expected when WINDINF is perpendicular to a thermal boundary, and this elevated convection had a lesser likelihood of damaging winds. By 0900 UTC, only a few scattered pockets of convec-

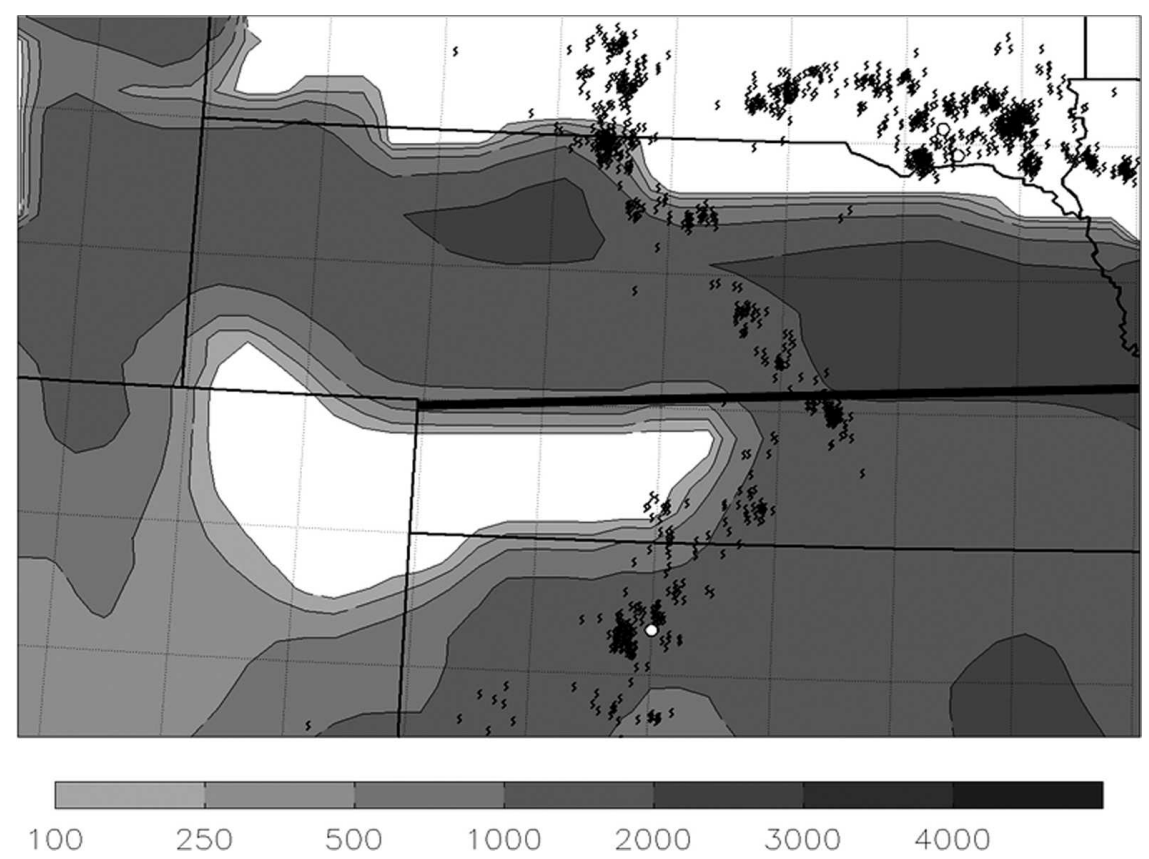

FIG. 13. RUC analysis of MLCAPE valid at 0600 UTC 8 Jul 2003. MLCAPE is shaded as shown and all other symbols are as in Fig. 5. 


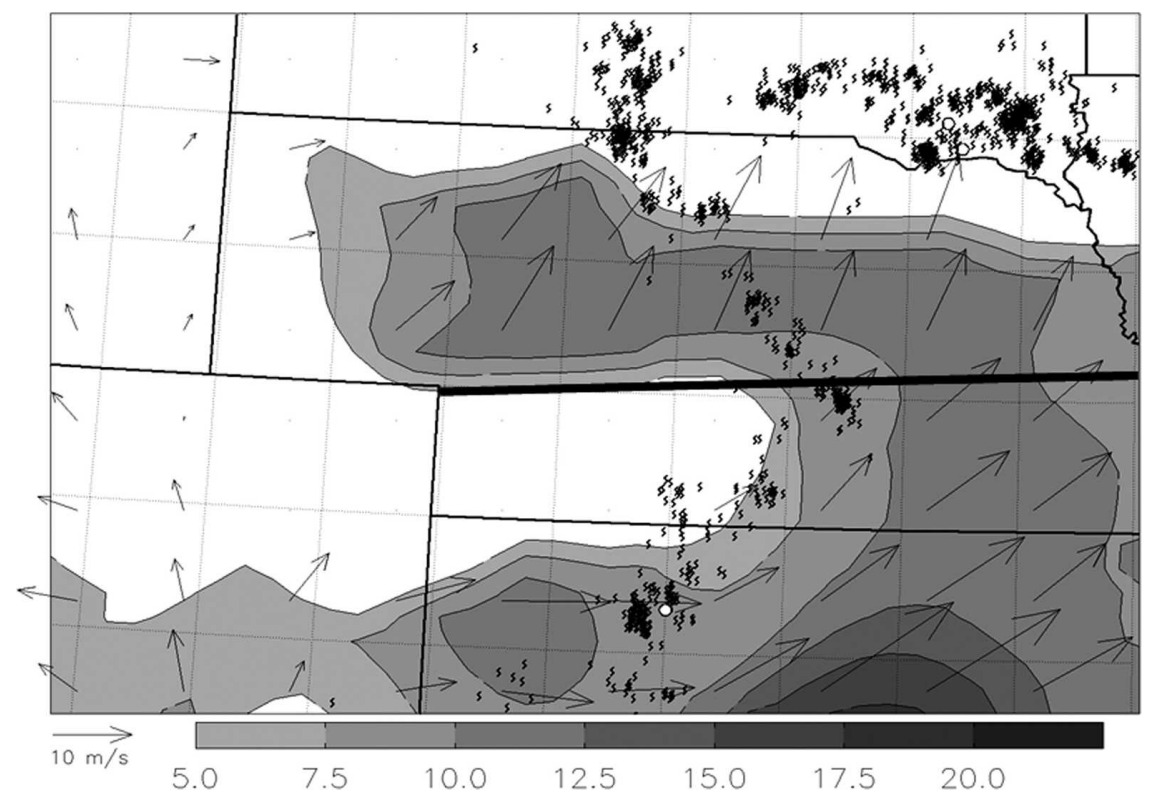

FIG. 14. Same as in Fig. 5 but valid at 0600 UTC 8 Jul 2003.

tion remained, with the exception of the elevated convection well north of the frontal boundary, even as DMGWIND indicated that damaging winds were still possible near the boundary.

\section{Summary}

Sounding parameters calculated from RUC model analyses were used to test the ambient conditions associated with severe convective winds. Over 500 model analyses were compared with over 7000 reports of severe convective winds from 2003. The sounding parameters calculated included variations of ground-relative wind velocity, wind shear, storm-relative helicity, instability, relative humidity, and other variables. Groundrelative wind velocity in the lowest few kilometers of the troposphere, but above the surface, was the most effective at discriminating between environments that produced damaging convective winds and those that produced ordinary convection. Large ambient groundrelative wind speeds in the lower troposphere, specifically near the top of a surface-based inflow layer, should be the highest consideration when forecasting long-lived damaging convective windstorms. These winds lead to fast-moving convective systems (with rapidly moving gust fronts), result in the shear necessary to maintain deep lifting on a gust front, and can be brought to the surface in downdrafts.

In addition to strong atmospheric wind fields, instability parameters were somewhat discriminatory between environments that produced damaging convective winds and those that produced ordinary convec- tion. CAPE and DCAPE were not as discriminatory as ground-relative winds, indicating that increases in instability may not be as important as increases in ground-relative wind fields when forecasting damaging winds. Midlevel relative humidity was also somewhat discriminatory, but not as discriminatory as the ambient wind fields. Dry air entrainment in the midlevels has been cited as a possible cause of downdraft initiation (e.g., Knupp 1987), but it appears that dry air in the midlevels is not uniquely associated with damaging winds. Many of the lapse rate parameters, particularly those near the surface, were not at all discriminatory between environments that produced damaging winds and those that produced convection. Previous research (e.g., Srivastava 1987) indicated that steep and unstable lapse rates were favorable for intense downdrafts, but these data indicate that precipitation processes and system-scale organization may be more important mechanisms for widespread damaging wind production. CIN parameters were also not very discriminatory. Although the reduction of CIN is necessary for initial convection initiation, it appears that once organized convection is mature, storm-scale and mesoscale processes are able to overcome any inhibition present and continue producing damaging winds given otherwise favorable conditions.

Because numerous sounding parameters were found to be useful when forecasting severe convective winds, WINDINF and DCAPE (the most skillful wind and thermodynamic parameters tested, respectively) were normalized and combined into a composite parameter 
(DMGWIND) that would indicate the possibility of damaging winds in a given environment with convection. The resulting output showed higher skill in separating damaging winds from nonsevere convection (using a threshold of 1.0) than the most skillful individual sounding parameter.

Case studies with strong convection (but not necessarily widespread damaging winds) were used to evaluate the sounding parameters and DMGWIND, and to examine atmospheric patterns where damaging winds occurred or did not occur. At some point during all the cases, sounding parameters indicated that damaging winds were possible. However, damaging winds generally did not occur when WINDINF was parallel to the convective line, as gust fronts there tended to move slowly, decreasing the surface wind speed. Additionally, damaging winds did not occur when WINDINF was perpendicular to the convective line, but blowing from warm to cold over a warm/stationary front, which tended to lead to elevated convection. These are the two apparent failure modes when strong convection is occurring and sounding parameters otherwise indicate a potential for damaging winds.

While identifying discriminatory parameters for damaging winds, this project did not fully investigate all of the possible physical causes for those damaging winds, and much work remains to be done in this area. Additionally, how the ambient environment impacts system organizational processes is important, and would benefit from further study. More work on the idea of elevated convection and how it impacts cold pool formation and damaging wind production would also be of significant benefit. Finally, further study of the gust front in a very stable lower troposphere would be beneficial, to determine what the relevant airflow patterns are in the updrafts and downdrafts.

Acknowledgments. The research reported in this paper was supported by graduate fellowships from the American Meteorological Society-National Weather Service and the University of Nebraska (for ELK). Additional support (for MDP) came from National Science Foundation Grant ATM-0349069. Data support came from the Air Force Combat Climatology Center, Atmospheric Radiation Measurement Program, National Center for Atmospheric Research, and Plymouth State College. Finally, the manuscript was greatly improved thanks to comments from two anonymous reviewers.

\section{REFERENCES}

Ashley, W. S., 2004: Derecho hazards in the United States. Preprints, 22d Conf. on Severe Local Storms, Hyannis, MA, Amer. Meteor. Soc., CD-ROM, J7A.2.
Atkins, N. T., and R. M. Wakimoto, 1991: Wet microburst activity over the southeastern United States: Implications for forecasting. Wea. Forecasting, 6, 470-482.

Benjamin, S. G., and Coauthors, 2004: An hourly assimilationforecast cycle: The RUC. Mon. Wea. Rev., 132, 495-518.

Brooks, H. E., C. A. Doswell III, and R. B. Wilhelmson, 1994: The role of midtropospheric winds in the evolution and maintenance of low-level mesocyclones. Mon. Wea. Rev., 122, 126-136.

Bunkers, M. J., B. A. Klimowski, J. W. Zeitler, R. L. Thompson, and M. L. Weisman, 2000: Predicting supercell motion using a new hodograph technique. Wea. Forecasting, 15, 61-79.

Byers, H. R., and R. R. Braham, 1949: The Thunderstorm Project. U.S. Weather Bureau, 298 pp. [NTIS PB234515.]

Corfidi, S. F., 2003: Cold pools and MCS propagation: Forecasting the motion of downwind-developing MCSs. Wea. Forecasting, 18, 997-1017.

_ J. H. Meritt, and J. M. Fritsch, 1996: Predicting the movement of mesoscale convective complexes. Wea. Forecasting, 11, 41-46.

Davies-Jones, R., 1984: Streamwise vorticity: The origin of updraft rotation in supercell storms. J. Atmos. Sci., 41, 29913006.

DOC/NOAA/NCEP/NWS SPC, cited 2003: Preliminary storm reports. [Available online at http://www.spc.noaa.gov/climo/.]

Evans, J. S., and C. A. Doswell III, 2001: Examination of derecho environments using proximity soundings. Wea. Forecasting, 16, 329-342.

Fritsch, J. M., and G. S. Forbes, 2001: Mesoscale convective systems. Severe Convective Storms, Meteor. Monogr., No. 50, Amer. Meteor. Soc., 323-357.

Fujita, T. T., and R. M. Wakimoto, 1981: Five scales of airflow associated with a series of downbursts on 16 July 1980. Mon. Wea. Rev., 109, 1438-1456.

Gilmore, M. S., and L. J. Wicker, 1998: The influence of midtropospheric dryness on supercell morphology and evolution. Mon. Wea. Rev., 126, 943-958.

Houze, R. A., Jr., 2004: Mesoscale convective systems. Rev. Geophys., 42, RG4003, doi:10.1029/2004RG000150.

Johns, R. H., and W. D. Hirt, 1987: Derechos: Widespread convectively induced windstorms. Wea. Forecasting, 2, 32-49.

Kelly, D. L., J. T. Schaefer, and C. A. Doswell III, 1985: Climatology of nontornadic severe thunderstorm events in the United States. Mon. Wea. Rev., 113, 1997-2014.

Kingsmill, D. E., and R. M. Wakimoto, 1991: Kinematic, dynamic, and thermodynamic analysis of a weakly sheared severe thunderstorm over northern Alabama. Mon. Wea. Rev., 119, 262-297.

Knupp, K. R., 1987: Downdrafts within high plains cumulonimbi. Part I: General kinematic structure. J. Atmos. Sci., 44, 9871008.

Kuchera, E. L., 2004: Identifying severe convective wind environments. M.S. thesis, Dept. of Geosciences, University of Nebraska at Lincoln, 172 pp.

Lee, W.-C., R. E. Carbone, and R. M. Wakimoto, 1992a: The evolution and structure of a "bow-echo-microburst" event. Part I: The microburst. Mon. Wea. Rev., 120, 2188-2210.

_, R. M. Wakimoto, and R. E. Carbone, 1992b: The evolution and structure of a "bow-echo-microburst" event. Part II: The bow echo. Mon. Wea. Rev., 120, 2211-2225.

Markowski, P. M., 2002: Hook echoes and rear-flank downdrafts: A review. Mon. Wea. Rev., 130, 852-876.

_, C. Hannon, J. Frame, E. Lancaster, A. Pietrycha, R. Ed- 
wards, and R. Thompson, 2003: Characteristics of vertical wind profiles near supercells obtained from the Rapid Update Cycle. Wea. Forecasting, 18, 1262-1272.

Orville, R. E., 1991: Lightning ground flash density in the contiguous United States-1989. Mon. Wea. Rev., 119, 573-577.

Peirce, C. S., 1884: The numerical measure of the success of predictions. Science, 4, 453-454.

Proctor, F. H., 1989: Numerical simulations of an isolated microburst. Part II: Sensitivity experiments. J. Atmos. Sci., 46, 2143-2165.

Rasmussen, E. N., and D. O. Blanchard, 1998: A baseline climatology of sounding-derived supercell and tornado forecast parameters. Wea. Forecasting, 13, 1148-1164.

Rotunno, R., J. B. Klemp, and M. L. Weisman, 1988: A theory for strong, long-lived squall lines. J. Atmos. Sci., 45, 463-485.

Schmidt, J. M., and W. R. Cotton, 1989: A high plains squall line associated with severe surface winds. J. Atmos. Sci., 46, 281301.

Srivastava, R. C., 1985: A simple model of evaporatively driven downdraft: Application to microburst downdraft. J. Atmos. Sci., 42, 1004-1023.

, 1987: A model of intense downdrafts driven by the melting and evaporation of precipitation. J. Atmos. Sci., 44, 17521774 .
Stoelinga, M. T., J. D. Locatelli, R. D. Schwartz, and P. V. Hobbs, 2003: Is a cold pool necessary for the maintenance of a squall line produced by a cold front aloft? Mon. Wea. Rev., 131, 95-115.

Thompson, R. L., R. Edwards, J. A. Hart, K. L. Elmore, and P. M. Markowski, 2003: Close proximity soundings within supercell environments obtained from the Rapid Update Cycle. Wea. Forecasting, 18, 1243-1261.

_ C. M. Mead, and R. Edwards, 2004: Effective bulk shear in supercell thunderstorm environments. Preprints, 22d Conf. on Severe Local Storms, Hyannis, MA, Amer. Meteor. Soc., CD-ROM, P1.1.

Wakimoto, R. M., 1985: Forecasting dry microburst activity over the high plains. Mon. Wea. Rev., 113, 1131-1143.

— , 2001: Convectively driven high winds. Severe Convective Storms, Meteor. Monogr., No. 50, Amer. Meteor. Soc., 255298.

Weisman, M. L., 1993: The genesis of severe, long-lived bow echoes. J. Atmos. Sci., 50, 645-670.

- and R. J. Rotunno, 2004: A theory for strong long-lived squall lines revisited. J. Atmos. Sci., 61, 361-382.

Wilks, D. S., 1995: Statistical Methods in the Atmospheric Sciences. Academic Press, 467 pp. 